\title{
Cloud condensation nucleus activity comparison of dry- and wet-generated mineral dust aerosol: the significance of soluble material
}

\author{
S. Garimella ${ }^{1}$, Y.-W. Huang ${ }^{1}$, J. S. Seewald ${ }^{2}$, and D. J. Cziczo ${ }^{1}$ \\ ${ }^{1}$ Department of Earth, Atmospheric and Planetary Sciences, Massachusetts Institute of Technology, Cambridge, MA, USA \\ ${ }^{2}$ Woods Hole Oceanographic Institution, Woods Hole, MA, USA
}

Correspondence to: D. J. Cziczo (djcziczo@mit.edu)

Received: 29 October 2013 - Published in Atmos. Chem. Phys. Discuss.: 27 November 2013

Revised: 28 March 2014 - Accepted: 11 May 2014 - Published: 18 June 2014

\begin{abstract}
This study examines the interaction of clay mineral particles and water vapor for determining the conditions required for cloud droplet formation. Droplet formation conditions are investigated for two common clay minerals, illite and sodium-rich montmorillonite, and an industrially derived sample, Arizona Test Dust. Using wet and dry particle generation coupled to a differential mobility analyzer (DMA) and cloud condensation nuclei counter, the critical activation of the clay mineral particles as cloud condensation nuclei is characterized. Electron microscopy (EM) is used in order to determine non-sphericity in particle shape. It is also used in order to determine particle surface area and account for transmission of multiply charged particles by the DMA. Single particle mass spectrometry and ion chromatography are used to investigate soluble material in wet-generated samples and demonstrate that wet and dry generation yield compositionally different particles. Activation results are analyzed in the context of both $\kappa$-Köhler theory $(\kappa-\mathrm{KT})$ and FrenkelHalsey-Hill (FHH) adsorption activation theory. This study has two main results: (1) $\kappa$-KT is the suitable framework to describe clay mineral nucleation activity. Apparent differences in $\kappa$ with respect to size arise from an artifact introduced by improper size-selection methodology. For dust particles with mobility sizes larger than $\sim 300 \mathrm{~nm}$, i.e., ones that are within an atmospherically relevant size range, both $\kappa$-KT and FHH theory yield similar critical supersaturations. However, the former requires a single hygroscopicity parameter instead of the two adjustable parameters required by the latter. For dry-generated particles, the size dependence of $\kappa$ is likely an artifact of the shape of the size distribution: there is a sharp drop-off in particle concentration at $\sim 300 \mathrm{~nm}$, and a
\end{abstract}

large fraction of particles classified with a mobility diameter less than $\sim 300 \mathrm{~nm}$ are actually multiply charged, resulting in a much lower critical supersaturation for droplet activation than expected. For wet-generated particles, deviation from $\kappa$ $\mathrm{KT}$ is likely a result of the dissolution and redistribution of soluble material. (2) Wet generation is found to be unsuitable for simulating the lofting of fresh dry dust because it changes the size-dependent critical supersaturations by fractionating and re-partitioning soluble material.

\section{Introduction}

Atmospheric aerosols play a significant role in the earth's climate system, especially in the radiative budget and the hydrological cycle. Their influence on climate is via the socalled direct and indirect radiative forcing effects (Denman and Brasseur, 2007). The direct effect of aerosols on atmospheric radiation is through the scattering and absorption of light in both the shortwave and long-wave regimes (Seinfeld and Pandis, 2006; Yu et al., 2006; Christopher et al., 2009). This interaction with radiation depends on optical properties that vary significantly among different aerosols and depend on the wavelength of incoming radiation, relative humidity, aerosol concentration, spatial distribution, and atmospheric dynamics (Seinfeld and Pandis, 2006; Yu et al., 2006; Christopher et al., 2009). Aerosols indirectly affect climate via their role in the formation and persistence of clouds in the atmosphere (Denman and Brasseur, 2007). As the availability and characteristics of aerosol particles vary, so do the 
formation, appearance, and persistence of clouds, which play a significant role in the climate system (Bergstrom et al., 2010; Logan et al., 2010; Lyapustin et al., 2010; Brock et al., 2011; Hansen et al., 2011; Lambe et al., 2011; McFarquhar et al., 2011; Booth et al., 2012).

In earth's atmosphere, the condensation of water vapor into liquid droplets does not occur in the absence of aerosol particles. These particles, which provide a surface onto which the water vapor can condense, are called cloud condensation nuclei $(\mathrm{CCN})$ because they facilitate the nucleation of droplets. Overall, the interaction of particulate matter and water vapor in the atmosphere is important for examining precipitation, cloud coverage, cloud persistence, and radiative forcing (Twomey, 1977; Albrecht, 1989; Forster and Ramaswamy, 2007).

According to the International Panel on Climate Change Fourth Assessment Report, scientific understanding of most aerosol indirect effects on clouds and precipitation is considered "very low" (Denman and Brasseur, 2007). Since clouds are a significant factor in earth's radiative budget, it is important to understand how aerosol particles serve as CCN and influence the formation and persistence of various types of clouds. Aerosol particle size, chemical composition, mixing state, and ambient environment are all factors thought to influence $\mathrm{CCN}$ activity and are therefore of significant interest (Forster and Ramaswamy, 2007).

Field observations of aerosol particles indicate that they have variable size distributions and can be composed of organic material, inorganic material, or a mixture of both (Shaw and Paur, 1983; Noble and Prather, 1996; Middlebrook et al., 1997; Dusek et al., 2006; Chou et al., 2008; Zhang et al., 2012). Therefore, laboratory studies of aerosol particles are necessary for determining how their various physical and chemical properties affect their ability to act as $\mathrm{CCN}$ in the atmosphere. Many previous studies investigated the nucleation potential both of individual types of aerosol particles (Raymond and Pandis, 2002, 2003; Petters and Kreidenweis, 2007a; Koehler et al., 2009; Sullivan et al., 2009, 2010a; Kumar et al., 2011a, b), and of simple mixtures (Raymond and Pandis, 2002, 2003; Bilde and Svenningsson, 2004; Abbatt et al., 2005). Observations indicate that the size of an aerosol particle is the primary factor in determining its efficiency as a CCN (Dusek et al., 2006); but its composition, though a secondary factor, should also be considered because it can affect how the particle will change due to the chemical interactions with its surroundings (Petters and Kreidenweis, 2007a; Rudich et al., 2007). Such interactions may arise from the transport of aerosol particles or interactions with sunlight, other particulate matter, or with water (Seinfeld and Pandis, 2006; Wong et al., 2011).

Among the individual types of aerosol particles previously investigated, mineral dust is of particular importance because of its high abundance in the atmosphere (Ganor and Mamane, 1982; Gano and Foner, 1996; Chou et al., 2008; Coz et al., 2009) and its demonstrated ability to nucleate cloud droplets (Ma et al., 2004; Furutani et al., 2008; Herich et al., 2009; Koehler et al., 2009; Sullivan et al., 2009, 2010; Lee et al., 2010; Kumar et al., 2011a, b). It is also important for primary production in oceans and rainforests because air masses laden with crustal material often transport limiting nutrients like iron and phosphorus (Duce et al., 1991; Jickells et al., 2005; Pett-Ridge, 2009). Mineral dust is lofted into the atmosphere when wind blows over arid soil, via a process known as saltation, and over half of wind-blown atmospheric aerosol originates from such sources (Tegen et al., 1996). Though mineral dust in the atmosphere mainly arises from naturally arid regions, it can also be mobilized anthropogenically, via land-use change, and is an additional aspect of the climate system changing over time (Forster and Ramaswamy, 2007). Recent satellite observations estimate that $25 \%$ of mineral dust comes from anthropogenic sources (Ginoux et al., 2012).

The behavior of mineral dust as a CCN depends on its physical and chemical properties. This study investigates the activation potential of two common clay minerals, illite and sodium-rich montmorillonite (NaMon), and an industrially derived sample, Arizona Test Dust (ATD), commonly used in aerosol and CCN studies. The particular dust samples considered in this study are commonly observed in the atmosphere (Usher et al., 2003) and/or have been studied previously (Herich et al., 2009; Kumar et al., 2011a, b). The empirical results from both this and previous works are interpreted with respect to the theoretical descriptions of warm cloud droplet activation, $\kappa$-Köhler theory $(\kappa-\mathrm{KT})$ and Frenkel-Halsey-Hill (FHH) adsorption activation theory. This study considers the effect of the generation method on activation potential using electron microscopy (EM), ion chromatography (IC), and Particle Analysis by Laser Mass Spectrometry (PALMS), comparing the results for dry- and wet-generated aerosol. Though many studies in the literature, e.g., Herich et al. (2009) and Koehler et al. (2009), have used both dry and wet particle generation, more recent work (Sullivan et al., 2009, 2010; Kumar et al., 2011b) has indicated that wet atomization of mineral dust particles leads to anomalous results in their activation. The effects of these artifacts are quantified, and their impacts on experimental results are considered.

\section{Theoretical framework}

\section{$2.1 \kappa-\mathrm{KT}$}

Köhler theory provides a theoretical basis for describing the equilibrium vapor pressure of a liquid droplet as it relates to the droplet's diameter (Köhler, 1936). It considers both the effects on saturation vapor pressure due a curved surface (the Kelvin effect) and the presence of a solute (Raoult's Law) (Köhler, 1936). Subsequently, this theory was adapted to account for differing solute hygroscopicity and to allow 
for easier parameterization in models (Junge and McLaren, 1971; Fitzgerald, 1973). A recent approach to describe the relationship between a particle's dry diameter, $D_{\mathrm{d}}$, and its activity as a $\mathrm{CCN}$ relates these two quantities by parameterizing a particle's hygroscopicity with a single parameter, $\kappa$ (Petters and Kreidenweis, 2007a). Derivation of $\kappa$-KT starts with the Kelvin relation for the saturation ratio over a curved surface:

$S=a_{\mathrm{w}} \exp \left(\frac{4 \sigma M_{\mathrm{w}}}{R T \rho_{\mathrm{w}} D}\right)$,

where $a_{\mathrm{w}}$ is the activity of water in solution, $\rho_{\mathrm{w}}$ is the density of water, $M_{\mathrm{w}}$ is the molecular weight of water, $\sigma$ is the surface tension of the edge of the droplet, $R$ is the universal gas constant, $T$ is temperature, and $D$ is the diameter of the droplet. In the $\kappa$-KT parameterization, the hygroscopicity parameter $\kappa$ is defined via the dependence of the activity of water in a solution on the solute hygroscopicity:

$\frac{1}{a_{\mathrm{w}}}=1+\kappa \frac{V_{\mathrm{s}}}{V_{\mathrm{w}}}$,

where $V_{\mathrm{s}}$ is the volume of the dry particulate matter and $V_{\mathrm{W}}$ is the volume of the water. The volumes in Eq. (2) can be expressed as equivalent diameters, since $D_{i}^{3}=6 V_{i} / \pi$. Solving Eq. (2) for $a_{\mathrm{w}}$ and substituting the result into Eq. (1), provides a relation for $S$ in terms of $D_{\mathrm{d}}$ (the dry particle diameter), $\kappa, S$, and $D$ :

$S(D)=\frac{D^{3}-D_{\mathrm{d}}^{3}}{D^{3}-D_{\mathrm{d}}^{3}(1-\kappa)} \exp \left(\frac{4 \sigma M_{\mathrm{w}}}{R T \rho_{\mathrm{w}} D}\right)$.

Determined experimentally, values for $\kappa$ lie between 0.5 and 1.4 for the most hygroscopic $\mathrm{CCN}$, such as salts; between 0.01 and 0.5 for moderately hygroscopic species; and approach zero for non-hygroscopic species (Petters and Kreidenweis, 2007a). Observational studies have shown that typical atmospheric aerosols have $\kappa$ between 0.1 and 0.4 (Andreae and Rosenfeld, 2008; Juranyi et al., 2010; Moore et al., 2011; Friedman et al., 2013; Lathem et al., 2013). For the materials considered in this study, hygroscopicity tandem differential mobility analyzer (HTDMA) measurements suggest that $\kappa=0.003$ for both dry- and wet-generated ATD, illite, and NaMon (Herich et al., 2009).

\subsection{FHH adsorption activation theory}

Studies of cloud nucleation on insoluble particles have suggested that condensation on such particles may occur via multilayer adsorption (McDonald, 1964). FHH adsorption activation theory has recently been suggested as a framework to describe CCN activity because it includes the effects of water adsorption on the insoluble component of the dust particles. It, like $\kappa$-KT, starts with the Kelvin relation (Eq. 1). However, the FHH framework includes an adsorption term in the Kelvin relation instead of the solute term, because it claims that including adsorption in a $\mathrm{CCN}$ activity model more accurately estimates the equilibrium growth of insoluble particles and better determines their critical supersaturation. To describe the formulation of FHH theory, $a_{\mathrm{w}}$ in Eq. (1) is replaced with an FHH isotherm, $a_{\mathrm{w}}=\exp \left(-A / \Theta^{-B}\right)$, where $\Theta$ is the Brunauer, Emmet and Teller (BET) isotherm:

$\Theta=\frac{c S}{(1-S)(1-S-c S)}$,

and $A$ and $B$ are parameters found using a least squares fit to empirical data. In Eq. (4), $c$ is a constant related to the heat of adsorption and $S$ is the saturation ratio of the gas. This formulation provides the expression for the equilibrium saturation ratio for a solution droplet according to FHH theory:

$$
S=\exp \left(-A / \Theta^{-B}\right) \exp \left(\frac{4 \sigma M_{\mathrm{w}}}{R T \rho_{\mathrm{w}} D}\right)
$$

In this treatment of FHH theory, the water activity is related to the of thickness of the adsorbed water via the BET multilayer equation of state for the adsorbed water layer (Henson et al., 2007; Kumar et al., 2009b). Therefore, the equilibrium saturation ratio for a droplet depends on the thickness of the adsorbed water layer via the activity of water. In $\kappa$-KT, however, the water activity in a solution instead depends on solute hygroscopicity.

\section{Methodology}

\subsection{Samples}

The dust types investigated are "Nominal 0-3 $\mu \mathrm{m}$ " ATD from Powder Technology Inc., illite (rock chips from Clay Mineral Society), and NaMon (unspecified size powder from Clay Mineral Society). In order to increase the number of particles in the size range corresponding to the accumulation mode in the atmosphere $(100-1000 \mathrm{~nm}$, in all cases diameter), all samples are ground in a Fisher Model 8-323V2 Mortar Grinder, using agate pestle and mortar, for $3 \mathrm{~h}$ in ethanol. This wet-grinding process is known to result in thinner crystalline sheets and is less likely to degrade clay crystallinity than dry grinding (Cicel and Kranz, 1981). Though grinding is required to generate particles of the desired sizes, it should be noted that this grinding technique might not reproduce natural weathering processes and could lead to particle properties, such as surface roughness, that are different from those observed in nature.

To assess the effect that grinding has on the activation behavior of the resulting powder, $\mathrm{CCN}$ activation is compared between ground and unground ATD. The size-dependent critical activation of the ground and unground ATD are identical within measurement uncertainty (Table 1), affirming 
that the grinding process does not change the activation behavior. Similar comparison with NaMon and illite is not possible since the unground samples are too coarse for readily aerosolizing. The IC experiments indicating similar soluble material concentrations in ground and unground samples are detailed in a later section.

\subsection{Experimental setup}

The setup for $\mathrm{CCN}$ activation experiments (shown in Fig. 1) consists of four parts: (1) aerosol generation, (2) aerosol size selection, (3) particle counting, and (4) CCN counting. A complementary series of observations are made with EM, IC, and single particle mass spectrometry: EM is used for observing particle morphology, and the latter two are used for investigating the composition and abundance of soluble species in the samples.

\subsubsection{Particle generation}

Dry generation of aerosols is accomplished via saltation. $\sim 4.5 \mathrm{~g}$ of mineral dust are placed in an Erlenmeyer flask that also contains three $1 \mathrm{~cm}$ Teflon-coated stir bars. This flask is shaken by a Lab Line 3589 Shaker to agitate the dust, and flowing air is introduced to suspend particles. The inlet of the flask is fitted with a filter to ensure that particle-free air enters the system. This method generates polydisperse aerosol particles with a size distribution that resembles naturally saltated dust (Lafon et al., 2006). Next, the flow is routed through an unshaken Erlenmeyer flask, used as a buffer volume in order to maintain a constant particle concentration and size distributions during an experiment. In order to assess the potential contribution of larger particles, this setup is compared to one that feeds the saltated dust into two URG Corporation cyclone impactors whose $50 \%$ cut sizes are $2.5 \mu \mathrm{m}$ and $1.0 \mu \mathrm{m}$ at $16.7 \mathrm{~L} \mathrm{~min}^{-1}$ flow (red arrows in Fig. 1). To agitate the dust, $2 \mathrm{~L} \mathrm{~min}{ }^{-1}$ of dry nitrogen is used and $14.7 \mathrm{~L} \mathrm{~min}^{-1}$ dry nitrogen is added to form the remainder of the flow. Any excess flow that is not drawn into the differential mobility analyzer (DMA) is vented into a fume hood using a T-connector (Fig. 1). Dry generation using either of these methods produces particle size distributions that are stable for several hours, even over several experimental days. The Results section reports averaged size distributions using measurements from before and after the activation experiments. With all samples, the before and after size distributions were equivalent within measurement uncertainty.

To wet-generate particles a Brechtel Manufacturing, Inc. (BMI) 9203 Aerosol Generator is used, which atomizes particles from a solution or slurry. In this study, slurries are created from 1.0 grams of sample mixed with $250 \mathrm{~mL}$ double distilled deionized 18.2 M $\Omega$ Millipore (DDI) water. The droplet-laden air stream enters an in-line dryer that desiccates the droplets such that only their dry nuclei exit the device. Since the flow out of the atomizer is $2 \mathrm{~L} \mathrm{~min}^{-1}$, a T-connector
Table 1. Comparison of uncorrected critical supersaturations for ground, unground, and wetted then re-dried ATD.

\begin{tabular}{lcccc}
\hline & $100 \mathrm{~nm}$ & $200 \mathrm{~nm}$ & $300 \mathrm{~nm}$ & $400 \mathrm{~nm}$ \\
\hline Ground & $0.62 \pm 0.04$ & $0.26 \pm 0.02$ & $0.24 \pm 0.02$ & $0.19 \pm 0.02$ \\
Unground & $0.59 \pm 0.01$ & $0.24 \pm 0.02$ & $0.21 \pm 0.01$ & $0.18 \pm 0.02$ \\
Re-dried & $0.60 \pm 0.01$ & $0.24 \pm 0.01$ & $0.21 \pm 0.02$ & $0.17 \pm 0.02$ \\
\hline
\end{tabular}

and filter are placed at its outlet to allow for the excess flow to escape.

\subsubsection{Particle sizing and counting}

The polydisperse flow (from either the dry or wet generation) is fed into a BMI 2002 DMA, which is fitted with an impactor whose $50 \%$ cut size is $650 \mathrm{~nm}$ at $1 \mathrm{~L} \mathrm{~min}^{-1}$ flow. Next, the flow passes through the neutralizer region of the DMA, where the polydisperse flow is imparted with a known (approximately Boltzmann) charge distribution using strips of Polonium-210. The particles are then sized based on their electrical mobility:

$Z_{\mathrm{p}}=\frac{n e C_{\mathrm{c}}}{3 \pi \mu D_{\mathrm{m}}}$,

where $n$ is the number of elementary electrical charges carried by the particle, $e$ is the charge of an electron, $C_{\mathrm{c}}$ is the Cunningham slip correction factor, $\mu$ is the dynamic viscosity of air, and $D_{\mathrm{m}}$ is the electrical mobility diameter (BMI, 2012). The output flow is pseudo-monodisperse in that it also contains multiply charged particles with electrical mobility diameters that are much larger than the desired diameter (Hurd and Mullins, 1962). Next, the particles pass through a flow splitter, where a portion $\left(0.36 \mathrm{~L} \mathrm{~min}^{-1}\right)$ of the monodisperse flow is routed to a BMI 1700 Mixing Condensation Particle Counter (MCPC) that records the total generated number concentration, $N_{\mathrm{T}}$, at $1 \mathrm{~Hz}$ frequency. Over the course of an experiment, the setup allows either for scans across a $10-1000 \mathrm{~nm}$ size range, i.e., scanning mobility particle sizer (SMPS) scans, or to set $Z_{\mathrm{p}}$ to a desired value. The DMA sheath flow is set to $5 \mathrm{~L} \mathrm{~min}^{-1}$ to maintain a fixed ratio with the sample flow rate. Though this ratio of sheath flow to sample flow is smaller than the typically desired $10: 1$ ratio, the presence of undesired effects on the resulting size distributions are checked using EM and PALMS.

\subsubsection{CCN counting}

The remaining $1 \mathrm{~L} \mathrm{~min}^{-1}$ of monodisperse flow from the DMA is fed into a subsequent flow splitter whose terminals feed into the two chambers in a Droplet Measurement Technologies Model CCN-200 Cloud Condensation Nuclei Counter (CCNC) (Roberts and Nenes, 2005; Lance et al., 2006). The CCNC measures the number concentration of particles that have condensed droplets, $N_{\mathrm{a}}$, via internal optical particle counters (OPCs) (Roberts and Nenes, 2005). 


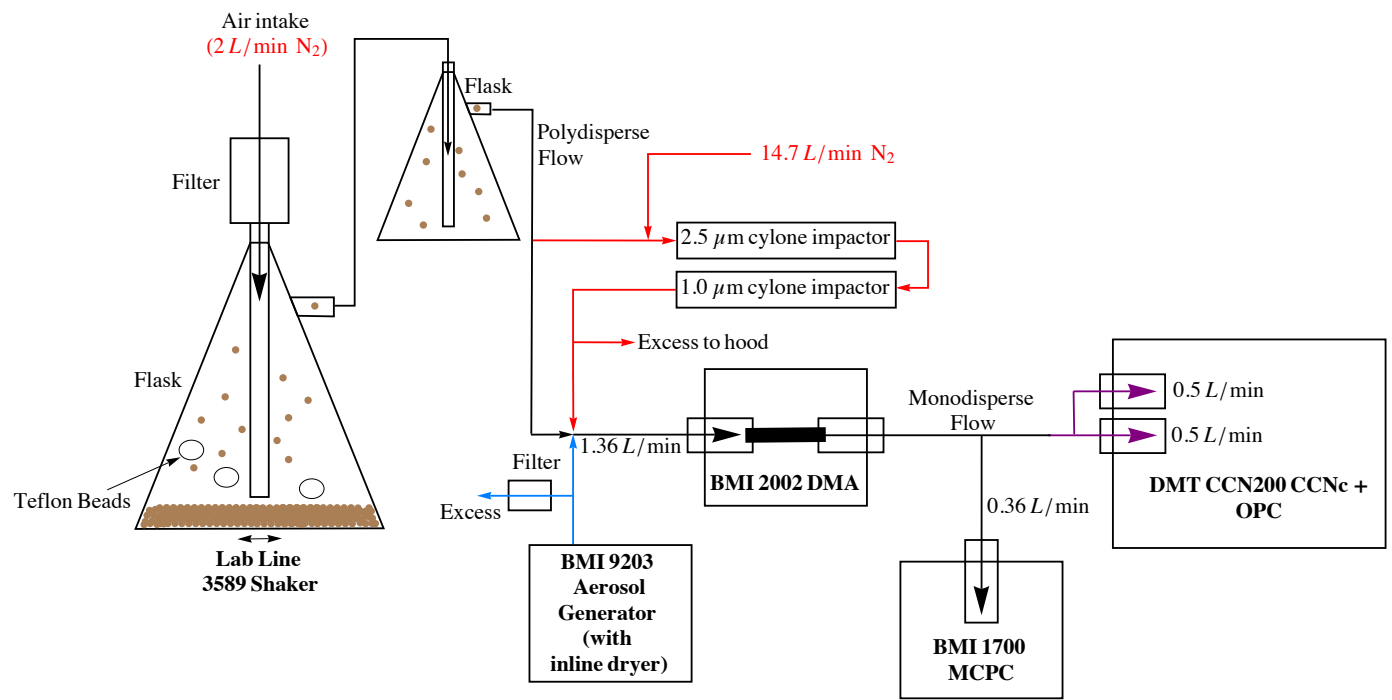

Figure 1. Diagram of experimental setup with flow rates. Blue arrows indicate the flow path and components used for particle generation from a water/dust slurry (wet generation). Red arrows indicate the flow paths for using cyclone impaction upstream of the DMA. Purple arrows show the configuration for $\mathrm{CCN}$ experiments.

Each of the two chambers in the CCNC draws $0.5 \mathrm{~L} \mathrm{~min}^{-1}$. The sum of these flow rates plus that drawn by the MCPC yields the total sample flow rate of $1.36 \mathrm{~L} \mathrm{~min}^{-1}$ through the system. The CCNC chambers are validated with 50, 80, and $100 \mathrm{~nm}$ ammonium sulfate particles to verify that they can reproduce literature values of critical supersaturation and a $\kappa$ for ammonium sulfate of 0.61 (Petters and Kreidenweis, 2007a). The results of this validation is shown in Fig. 2.

The two columns in the CCNC can be set to a range of supersaturations, $S S$. For the purpose of this study, chamber A scans over $S S=0.07,0.1,0.3$, and 0.05 , while chamber B scans over $S S=0.7,0.5,0.3$, and 0.71 . The first three supersaturations (for both chambers) have a six-minute duration. Each of the last three minutes at a given supersaturation is taken as a single data point, leading to three measurements per supersaturation. The final supersaturation in each chamber ( 0.05 and 0.71 , respectively) lasts for $2 \mathrm{~min}$ and is included for equilibrating the CCNC before starting the next scan. The $S S$ values for this last step are selected to be outside the typical operational range of the $\mathrm{CCNC}$ so they can be removed as adjustment periods in the data. Running a sample at a specific size requires $18 \mathrm{~min}$, with an additional $2 \mathrm{~min}$ to equilibrate the column temperatures and switch to the next size with the DMA. In a single scan, the fraction of activated $\mathrm{CCN}$ is reported at supersaturations of $S S=0.07,0.1,0.3$, 0.5 , and 0.7 . The supersaturation at which $50 \%$ of the particles activate into droplets is called the critical supersaturation, $S S_{\text {crit }}$, which is found by fitting a sigmoid curve to the $N_{\mathrm{a}} / N_{\mathrm{T}}$ vs. $S S$ data. Since both chambers simultaneously collect data for $S S=0.3$, a comparison is made to verify that $S S$ and $N_{\mathrm{a}}$ are comparable between the chambers.

\subsubsection{Ion chromatography}

Examination of the soluble components of the mineral dust is accomplished using IC. Samples are prepared by mixing $0.5 \mathrm{~g}$ of each of the ground and unground powders with $50 \mathrm{~mL}$ of DDI water, and filtering the resulting supernatant successively though $0.45 \mu \mathrm{m}, 0.2 \mu \mathrm{m}$, and $0.02 \mu \mathrm{m}$ sterile syringe filters to produce a solution of the soluble species in the sample. Anions and cations are analyzed using a Dionex DX500 ion chromatograph equipped with electrochemical suppression and a conductivity detector. For anions, a Dionex AS15 analytical column is used with a sodium hydroxide eluent. For cations, a CS12A analytical column is used with a sulfuric acid eluent. The measurable cations are sodium, lithium, potassium, calcium, magnesium, strontium, and ammonium. The measurable anions are chloride, bromide, nitrate, sulfate, and fluorine. This list accounts for the most likely ions to be leached from clay minerals (Wenk and $\mathrm{Bu}-$ lakh, 2004).

\subsubsection{Electron microscopy}

Transmission EM is used to investigate the morphological properties of the aerosol particles considered in this study. In order to analyze samples, they are generated and size-selected as described above and then are collected using a conventional impactor, similar to the Micro-Orifice Uniform-Deposit M135-10 impactor. Particles are impacted onto Electron Microscopy Sciences FCF200 gold microscope grids with formvar carbon support film. Grid analysis is performed at the MIT Center for Materials Science and Engineering using a JEOL 2010 Advanced High Performance TEM for determining the sizes and aspect ratios of the 

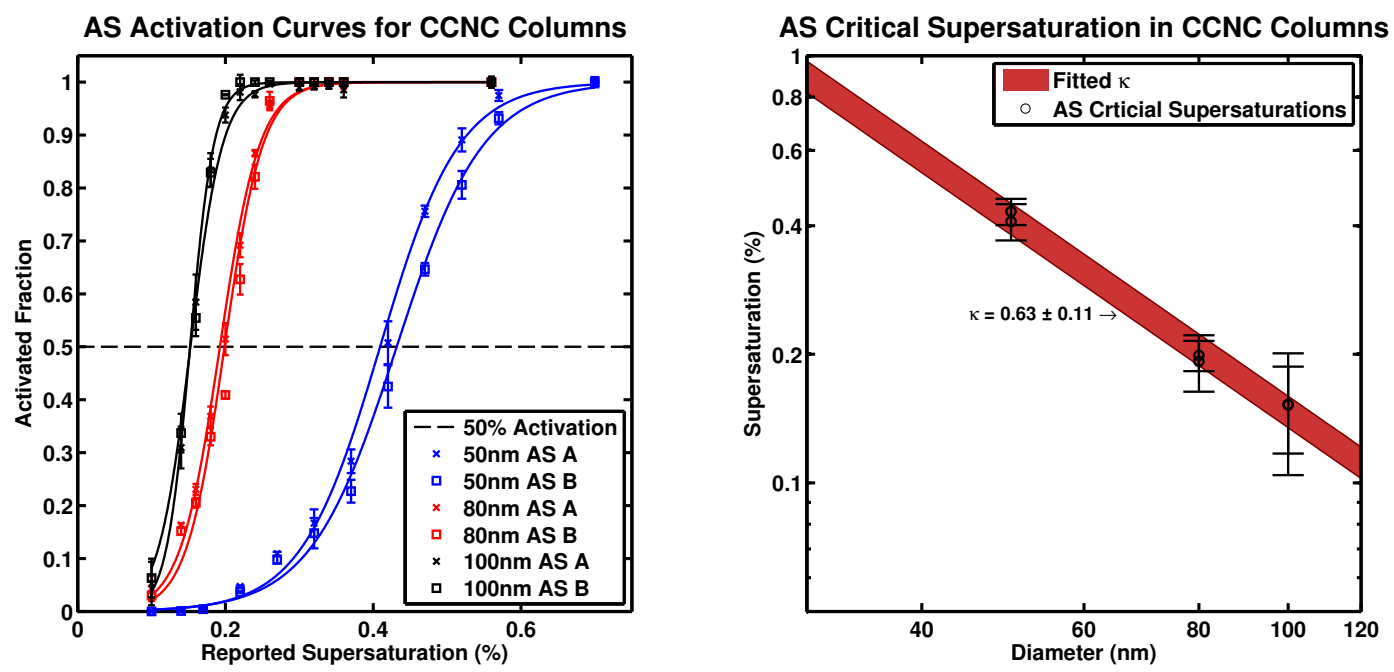

Figure 2. Left: AS Activation Curves for 50, 80, and $100 \mathrm{~nm}$ particles in the A and B columns of the CCNC. Right: critical supersaturation as a function of mobility diameter from the interpolated $50 \%$ activation points from the curves on the left. A $\kappa$ value of $0.63 \pm 0.11$ corresponds well with the literature value of $\kappa_{\mathrm{AS}}=0.61$ (Petters and Kreidenweis, 2007a) and provides validation of the CCNC setup.

particles. Additionally, the energy-dispersive X-ray (EDX) spectroscopy functionality of this microscope enables characterization of the samples based on elemental abundance.

Approximately 50 particles per size per species per generation method are used to perform the shape and charge corrections. Particle concentrations during experiments are $\sim 30-90$ particles per $\mathrm{cm}^{3}$, so using the number of particles measured by the CCNC for a given data point ( $1 \mathrm{~min}$ of data) as the population size for an activation experiment gives $N \sim 15000-45000$. Using a typical standard deviation of a lognormal fit to the EM data of $\sigma=35$, the sampling uncertainty at the $95 \%$ confidence level after population size correction is $10 \%$. The sampling was randomized by choosing a subsection of the microscope grid at low magnification and then proceeding to measure the particles in that section.

\subsubsection{Particle analysis by laser mass spectrometry}

PALMS (Murphy and Thompson, 1995; Cziczo et al., 2006) is used to investigate the aerodynamic size and chemical composition of monodisperse dust particles. The chemical differences in dry- and wet-generated particles are of particular interest. Spectra are collected on a particle-by-particle basis and 1000 spectra are gathered per sample per size. Aerosol particles enter PALMS via an aerodynamic inlet. An Nd:YAG laser beam is split into two beams to detect the particle, using the time between scattering events to provide aerodynamic size information. Next, a $193 \mathrm{~nm}$ excimer laser is triggered to ablate and ionize the particle. The ions from the particle are sent through a reflectron and registered on a microchannel plate to record a mass spectrum for the particle. Both positive and negative mass spectra are recorded for the dust samples.

\subsection{Data processing}

\subsubsection{Charge correction}

Particles passing through the charge neutralizer in the DMA are imparted with an equilibrium charge distribution that can be approximated by a Boltzmann distribution (BMI, 2012). As done in Moore et al. (2010) and Kumar et al. (2011a, b), the fraction of particles with a particular charge can be calculated using the calculations in Wiedensohler et al. (1988). With this technique, measuring the incoming polydisperse size distribution allows for the determination of the number of multiply charged particles in the monodisperse output. Specifically, since the larger particles will activate first, the fraction of multiply charged particles for a given size is subtracted from the activation curve, and the curve is then rescaled to include only singly charged particles (Fig. 3). The fraction of larger, multiply charged particles are observed with EM and are compared to the calculated values.

When determining the incoming polydisperse size distribution into the DMA, charge corrections are applied that reassign multiply charged particles to the correct size bins, assuming that a known fraction of each bin is multiply charged (BMI, 2012). This procedure produces a charge-corrected size distribution. This method is appropriate for size distributions that are smooth but creates an artifact for distributions that do not span the entire range of a scan, which is the case for dry-generated mineral dust. As discussed in Petters et al. (2007b), DMA-selected monodisperse aerosol must come from the correct region of a polydisperse aerosol for accurate hygroscopicity measurements. To this effect, Fig. 4 illustrates how selecting particles from the lower tail of such a distribution yields only multiply charged particles, leading to a significant data artifact. Since the selected particles are 

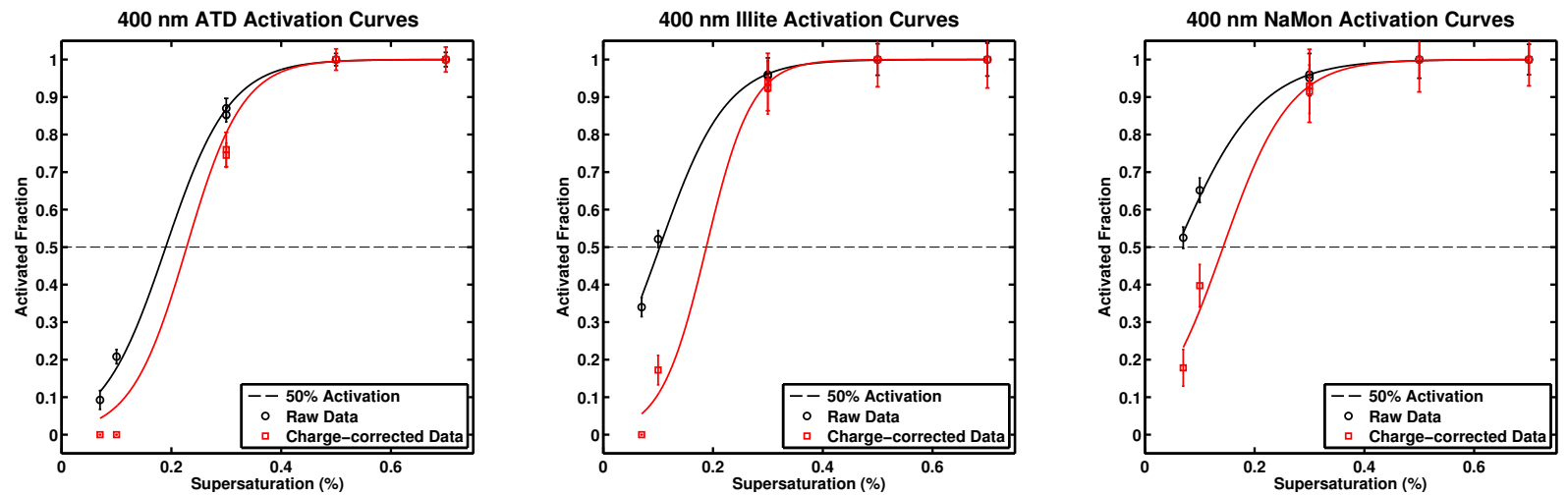

Figure 3. Activation curves for the three dusts, size-selected at $400 \mathrm{~nm}$. In black are uncorrected results, with sigmoid fits, and in red are charge-corrected results with sigmoid fits. The calculations in Wiedensohler (1988) and EM observations both indicate that fraction of multiply charged particles at this size is $\sim 0.4$. The uncertainty associated with this charge correction technique is shown by the y-error bars in all critical supersaturation vs. diameter plots in this work.

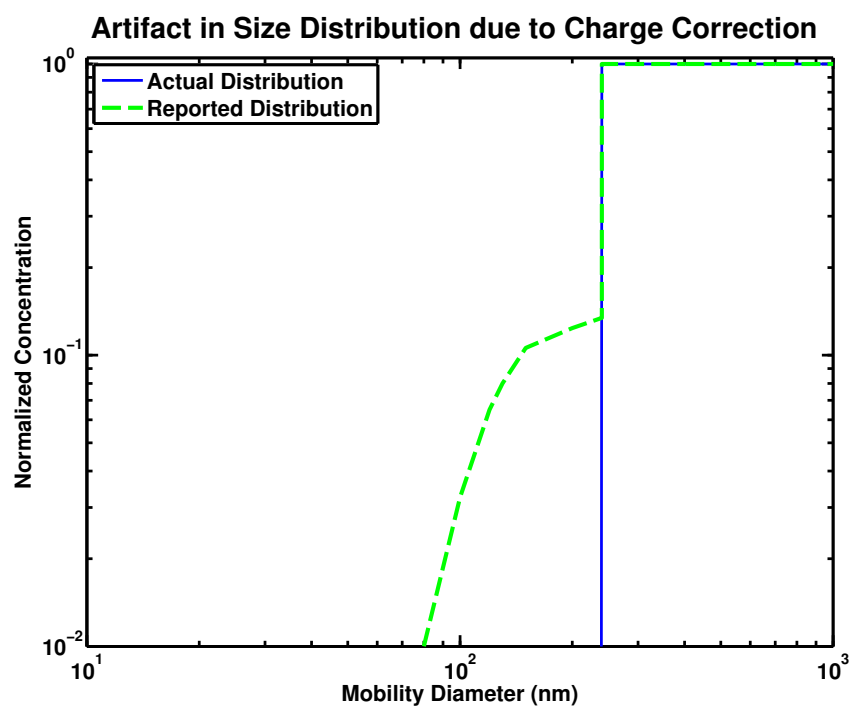

Figure 4. Artifact introduced into a idealized step function size distribution due to SMPS charge corrections. The "actual" idealized size distribution is shown in blue, and the size distribution reported by a DMA (after charge correction) is shown in dashed green. The difference between the two distribution arises from misassigning correctly sized particles to smaller size bins, as would be done for multiply charged particles. The two sloped regions in the green curve correspond to the singly charged particles misassigned as doubly or triply charged.

much larger than the desired size, this artifact prevents the accurate determination of size-dependence in hygroscopicity. As shown in a later section, this lack of correctly sized particles is supported by EM results: for electrical mobility sizes smaller than $\sim 300 \mathrm{~nm}$, EM shows only multiply charged particles whose diameters are much larger than the desired size.

\subsubsection{Shape correction}

A particle's electrical mobility diameter, $D_{\mathrm{m}}$, is defined as the diameter of a sphere with the same electrical mobility as the particle. Therefore, the $D_{\mathrm{m}}$ of a particle corresponds to its actual diameter if the particle is spherical (DeCarlo et al., 2004). For a non-spherical particle the electrical mobility is insufficient for determining the surface area that is available for interactions with water (DeCarlo et al., 2004; Kumar et al., 2011a). The volume-equivalent diameter, $D_{\text {ve }}$, of a particle is defined as the diameter of a sphere with the same volume as an irregularly shaped particle. The relationship between $D_{\mathrm{m}}$ and $D_{\mathrm{ve}}$ is typically analyzed using tandem electrical mobility and aerodynamic particle sizing in order to determine the dynamic shape factor, $\chi$, of the irregularly shaped particle (DeCarlo et al., 2004; Kumar et al., 2011a). The character $\chi$ is defined as the ratio of drag force experienced by the irregularly shaped particle to that experienced by a sphere with equivalent volume as both move through a gas at the same velocity (DeCarlo et al., 2004). A spherical particle has $\chi=1 . D_{\mathrm{m}}$ and $D_{\mathrm{ve}}$ can be related by $D_{\mathrm{m}} / C_{\mathrm{c}}\left(D_{\mathrm{m}}\right)=\chi D_{\text {ve }} / C_{\mathrm{c}}\left(D_{\mathrm{ve}}\right)$, with $\chi \geq 1$. Since $C_{\mathrm{c}}$ monotonically decreases with increasing particle size, $D_{\mathrm{m}}$ is always lager than $D_{\text {ve }}$ for non-spherical particles. Therefore, knowing a particle's electrical mobility diameter provides an upper bound for the volume of a non-spherical particle.

The clay minerals considered in this study are nonspherical. They have a layered chemical structure and a flat or sheet-like morphology (Wenk and Bulakh, 2004). Mineral dust particles are approximated as elliptical cylinders with major axis, $d_{\mathrm{M}}$, and minor axis, $d_{\mathrm{m}}$, and maximum thickness, $h_{\max }$, which is constrained by mobility sizing. The expression for the maximum thickness is

$h_{\max }=\frac{2 D_{\mathrm{m}}^{3}}{3 d_{\mathrm{M}} d_{\mathrm{m}}}$. 
Electron micrographs provide a means of determining the dimensions of the cylindrical face, and the particle's mobility diameter provides an upper bound on the height by bounding its volume. The micrographs can also indicate whether a particle is being observed edge-on or face-on because a particle's face does not exhibit the stratified structure that an edge does. For each sample, direct EM observations exist for dry-generated particles with $D_{\mathrm{m}}=200$ and $400 \mathrm{~nm}$, and for wet-generated particles of $D_{\mathrm{m}}=50,100$, and $400 \mathrm{~nm}$. Since wet-generated NaMon has a unimodal size distribution, EM observations at $D_{\mathrm{m}}=50$ and $400 \mathrm{~nm}$ are sufficient to investigate its morphology as a function of size.

As a particle's thickness approaches zero, its surface area equals twice the face area. Per Kumar et al. (2011a) and Kumar et al. (2011b), the surface area equivalent diameter, $D_{\mathrm{se}}$, is defined as the diameter of a sphere having the same surface area as an irregularly shaped particle. Assuming particles have a non-zero height and volume less than a sphere of diameter $D_{\mathrm{m}}$, the bounds on $D_{\mathrm{se}}$ are

$$
\sqrt{\frac{1}{2} d_{\mathrm{M}} d_{\mathrm{m}}}<D_{\mathrm{se}}<\sqrt{\frac{1}{2} d_{\mathrm{M}} d_{\mathrm{m}}+\frac{1}{3}\left(d_{\mathrm{M}}+d_{\mathrm{m}}\right) \frac{D_{\mathrm{m}}^{3}}{d_{\mathrm{M}} d_{\mathrm{m}}}} .
$$

The effects of charge and shape corrections for correctly sized, dry-generated particles are shown in Table 2, and those for dry-generated ATD are seen in Fig. 5. Charge-corrected critical supersaturations are higher than uncorrected ones because the contribution of multiply charged particles is removed. Shape-corrected surface area equivalent diameters tend to be larger than their corresponding mobility diameters because of particle non-sphericity. The effects of charge and shape correction are of similar importance for ATD. The shape corrections for all the samples have similar increases in equivalent diameter, but the effects of charge correction for illite and NaMon are more significant because of their lower uncorrected critical supersaturations.

\section{Results}

The size-dependent particle concentration for dry-generated (black squares), wet-generated (blue squares), and drygenerated cyclone impacted (red squares) particles were determined using SMPS scans for each dust type and dispersion method (Fig. 6). The dry-generated particles are most prevalent at larger sizes, and the concentration is significantly less for sizes below $\sim 300 \mathrm{~nm}$. The wet-generated size distributions are all significantly different from their dry counterparts. The size distribution of the dry-generated cycloneimpacted particles resembles that of the dry-generated particles, but the overall concentration of particles is lower and the peak concentration is shifted to a smaller size. For ATD and illite, the wet distributions are bimodal, and for NaMon the peak of the wet distribution is shifted to a smaller size. As noted above, previous studies have indicated that wet generation methods introduce a significant artifact that is not found

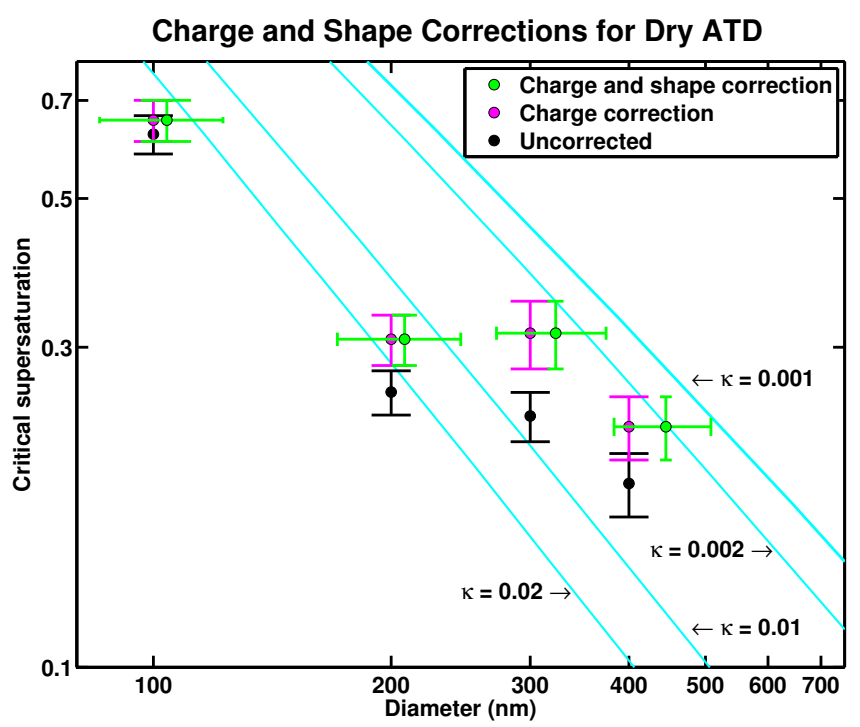

Figure 5. Critical supersaturation as a function of size for drygenerated ATD. Raw data (black) are shown along with charge corrections (magenta) and charge and shape corrections (green). Dashed cyan curves are lines of constant $\kappa$. Particle sizes are corrected for their non-spherical shape by estimating their surface area from EM. After shape correction, particles are classified by their surface area equivalent diameters instead of by their mobility diameters. The y-error bars indicate the standard deviation of measured supersaturation. The x-error bars indicate the range of possible values of surface area equivalent diameter as observed with EM.

with dry dispersion, i.e., atomized aerosols may contain soluble contaminants or metastable hydrates that are not found in dry-dispersed aerosols (Sullivan et al., 2009, 2010; Kumar et al., 2011b). With respect to the size distribution, this artifact corresponds to the peak at $\sim 50 \mathrm{~nm}$ that is not present in the dry distributions (Fig. 6).

The second row of Fig. 6 shows the charge- and shapecorrected dust activation data. In order to determine if the DMA output is sufficiently monodisperse, EM is used. Accordingly, squares show data where EM confirms the presence of correctly sized particles. Stars show data for which EM shows only multiply charged particles. Such particles have observed diameters that are much larger than the desired size. For the correctly sized dry-generated particles, $\kappa$ ranges from $0.001-0.01$. For wet-generated and incorrectly sized particles, the range for $\kappa$ increases dramatically to $0.01-0.45$. For the larger sizes of illite and NaMon, wet generation did not have a drastic effect on the observed critical supersaturation. However for ATD, the critical supersaturation of the wet-generated dust is significantly lower than that for dry-generated dust. This change in nucleation behavior using wet generation is not observed when the dust is simply wetted and re-dried. Nucleation experiments were repeated with wetted and re-dried dust, and the results were identical (within measurement uncertainty) to those of the original dry dusts (Table 1). 
Table 2. Charge and shape corrections to critical supersaturations of dry particles.

\begin{tabular}{lcccc}
\hline & $\begin{array}{c}\text { Uncorrected } \\
S S_{\text {crit }}\end{array}$ & $\begin{array}{c}\text { Charge- } \\
\text { corrected } \\
S_{\text {crit, cc }} / S_{\text {crit }}\end{array}$ & $\begin{array}{c}\text { Shape- } \\
\text { corrected } \\
D_{\text {se }} / D_{\mathrm{m}}\end{array}$ & $\begin{array}{c}\text { Charge- and shape- } \\
\text { corrected } \\
D_{\text {se }}, S S_{\text {crit, cc }}\end{array}$ \\
\hline ATD & $0.24 \pm 0.02$ & 1.33 & $0.91-1.25$ & $\begin{array}{c}272-374 \mathrm{~nm}, \\
0.31 \pm 0.04\end{array}$ \\
$D_{\mathrm{m}}=300 \mathrm{~nm}$ & & & & $383-508 \mathrm{~nm}$, \\
$\mathrm{ATD}$ & $0.19 \pm 0.02$ & 1.22 & $0.95-1.27$ & $0.23 \pm 0.02$ \\
$D_{\mathrm{m}}=400 \mathrm{~nm}$ & & & & $337-422 \mathrm{~nm}$, \\
$\mathrm{Illite}$ & $0.12 \pm 0.02$ & 1.54 & $1.12-1.41$ & $0.19 \pm 0.04$ \\
$D_{\mathrm{m}}=300 \mathrm{~nm}$ & & & & $449-563 \mathrm{~nm}$, \\
$\mathrm{Illite}$ & $0.096 \pm 0.02$ & 1.80 & $1.12-1.41$ & $0.17 \pm 0.05$ \\
$D_{\mathrm{m}}=400 \mathrm{~nm}$ & & & & $369-453 \mathrm{~nm}$, \\
NaMon & $0.08 \pm 0.03$ & 1.90 & $1.23-1.51$ & $0.15 \pm 0.05$ \\
$D_{\mathrm{m}}=300 \mathrm{~nm}$ & & & & $492-604 \mathrm{~nm}$, \\
NaMon & $0.06 \pm 0.03$ & 1.99 & $1.23-1.51$ & $0.13 \pm 0.06$ \\
$D_{\mathrm{m}}=400 \mathrm{~nm}$ & & & & \\
\hline
\end{tabular}

Shape determination using electron micrographs show that approximating particle geometry as flat and cylindrical is appropriate for the purpose of shape correction (Fig. 6). The images indicate that particles are often larger than their intended mobility size. This is a consequence of the sizing artifact illustrated in Fig. 4. Incorrect sizing occurs when attempting to sample from the lower tail of the size distribution where most particles are incorrectly sized. Classifying particles by their mobility-equivalent diameters is only appropriate if the abundance of singlets is much higher than that of multiply charged particles in the actual size distribution.

Accounting for multiply charged particles considerably increases the required supersaturation for droplet activation even before considering the sizing artifact (Figs. 3 and 5). Using observations of particle geometry for determining surface area also leads to an increase in particle size. Shape corrections are applied only to particles that are sized correctly according to their electrical mobility (squares in Fig. 6). For correctly sized particles, the fraction of multiply charged particles, as calculated using the equations in Wiedensohler (1988), matches (within measurement uncertainty) the fraction observed using EM even with a ratio of sheath to sample flow of less than 10:1. However, when EM results indicate that the majority of particles are doublets and triplets (stars in Fig. 6), mineral dust of the desired size is not present in the sample. In these cases no shape correction is performed since the measurement would not be for particles of the correct size and/or composition.

The EM results indicate the importance of characterizing the size distribution of particles output by a DMA, especially when there is an abundance of large particles in the polydisperse size distribution. Using cyclone impaction efficiently removes the larger particles before applying a Boltzmann charge distribution, and the downstream particle distribution is closer to monodisperse (Fig. 7). The PALMS results indicate that the distributions peak at the desired size and that the majority of doublets and triplets are removed even with a ratio of sheath to sample flow of less than $10: 1$. Therefore, when the influence of larger particles is diminished, standard charge correction procedures (Wiedensohler et al., 1988) are sufficient to account for the remaining particles. Though EM would be required for determining the exact degree of shape correction required, these corrections are less important when the larger particles are efficiently removed and no sampling is performed in the lower tail of the size distribution.

The wet generation artifact manifests as a mode of soluble non-mineral particles whose influence is observable using IC, EM, and PALMS. Figure 8 shows the results from the IC analysis of the soluble portions of the clay samples, which likely comprises the smaller mode seen in the size distributions. The ground and unground results are similar, and the grinding process does not systematically increase or decrease the amount of dissolved material. NaMon leaches more sodium but less significant quantities of the other materials than the other clays. This increase is likely observed because NaMon is a swelling clay, where the mineral layers are less tightly bound and therefore hydrate more efficiently (Foster, 1953; Poppe et al., 2001). The smaller $(<100 \mathrm{~nm})$ mobility diameter peak in the ATD and illite wet-generated size distributions is likely comprised of leached soluble material. Since water can more easily permeate between layers in NaMon, the unimodal wet-generated size distribution is likely a result of the retention of water by particles after wetting. The sizes of salt particles formed from wet generation can be estimated by summing the concentration of all dissolved material measured by the IC and assuming a typical density for the resulting salts of $2.3 \mathrm{~g} \mathrm{cc}^{-1}$. Since the 

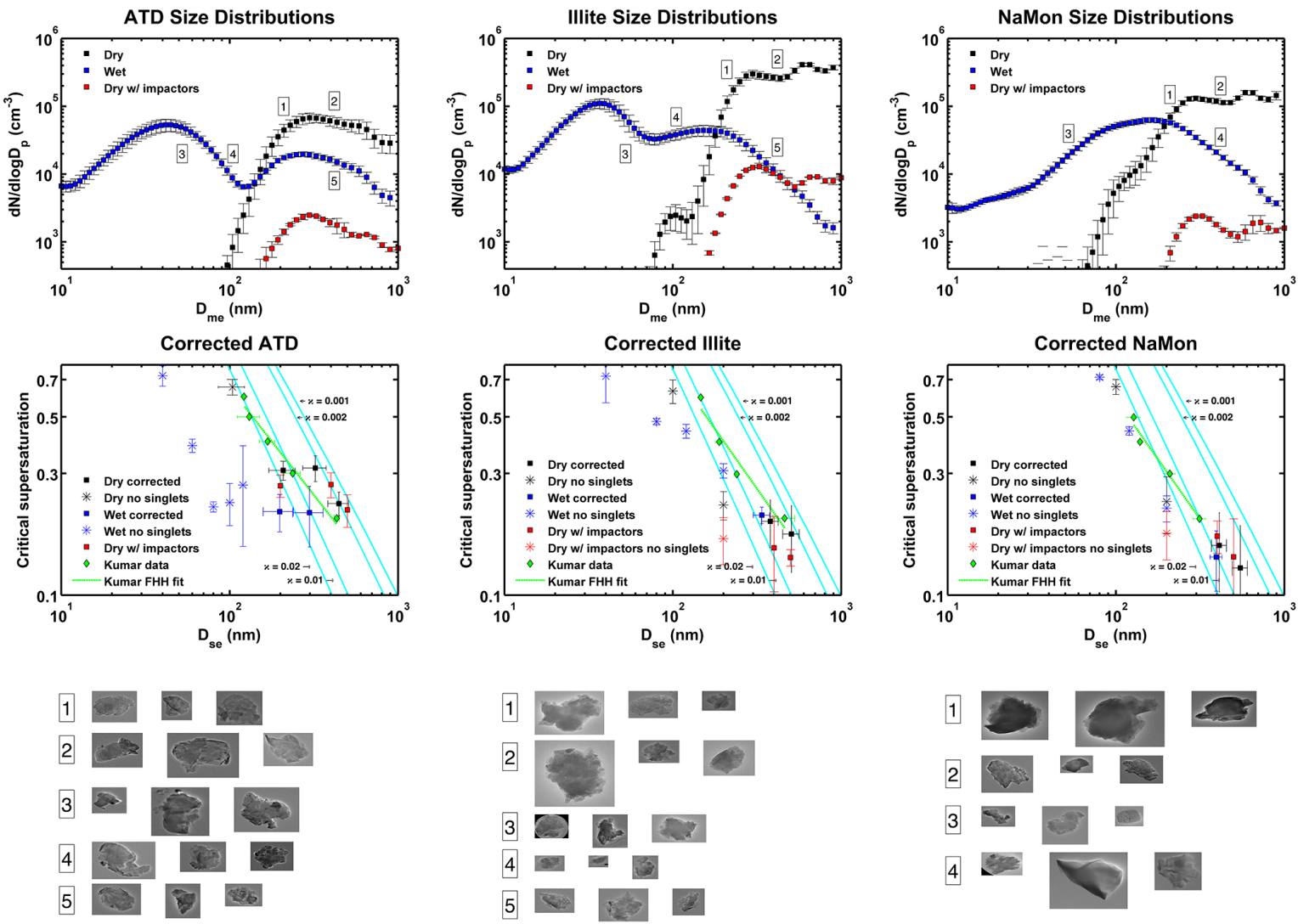

Figure 6. Top row: size distributions for the wet-generated (blue), dry-generated (black), and cyclone-impacted dry-generated (red) samples. Boxed numbers adjacent to the blue and black distributions indicate the sizes that were analyzed with electron microscopy. Note the difference between wet and dry generation. For the non-swelling materials (ATD and illite) the wet-generated distributions are bimodal. For NaMon, a swelling clay, the wet-generated distribution is unimodal. Cyclone impaction reduces the overall concentration of particles entering the DMA and shifts the peak concentration to a smaller size. Middle row: charge- and shape-corrected results from this study in blue and black, charge-corrected and cyclone-impacted data in red, lines of constant $\kappa$ in cyan, and data from Kumar et al. (2011b) in green. The blue and black squares represent particle sizes for which the shape correction in this paper can be applied. The blue and black stars represent particle sizes for which the shape correction cannot be applied because only multiply charged particles with observed diameters that are much larger than the desired size, not singlets, are observable on the microscope grid. Bottom row: typical images from the EM analysis. The boxed numbers on the left of the images correspond to the sizes indicated in the first row of this figure.
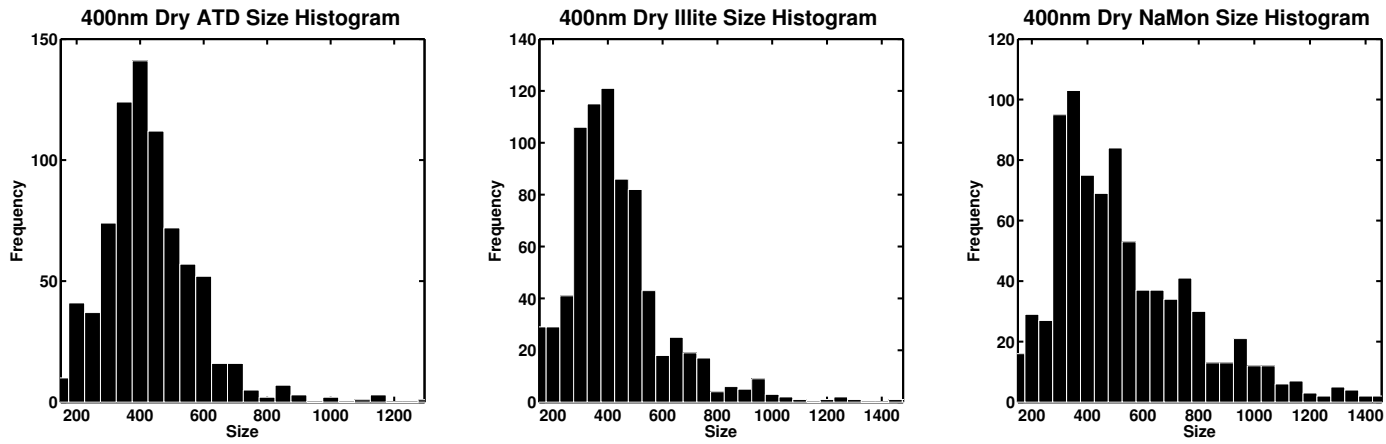

Figure 7. Aerodynamic size distributions obtained from PALMS. Sizes are recorded downstream of the DMA, which is set to select $400 \mathrm{~nm}$ particles. The peaks of the distributions are at the desired size, indicating that the majority of doublets and triplets are removed. Standard charge correction procedures (Wiedensohler et al., 1988) account for the remaining large particles. 

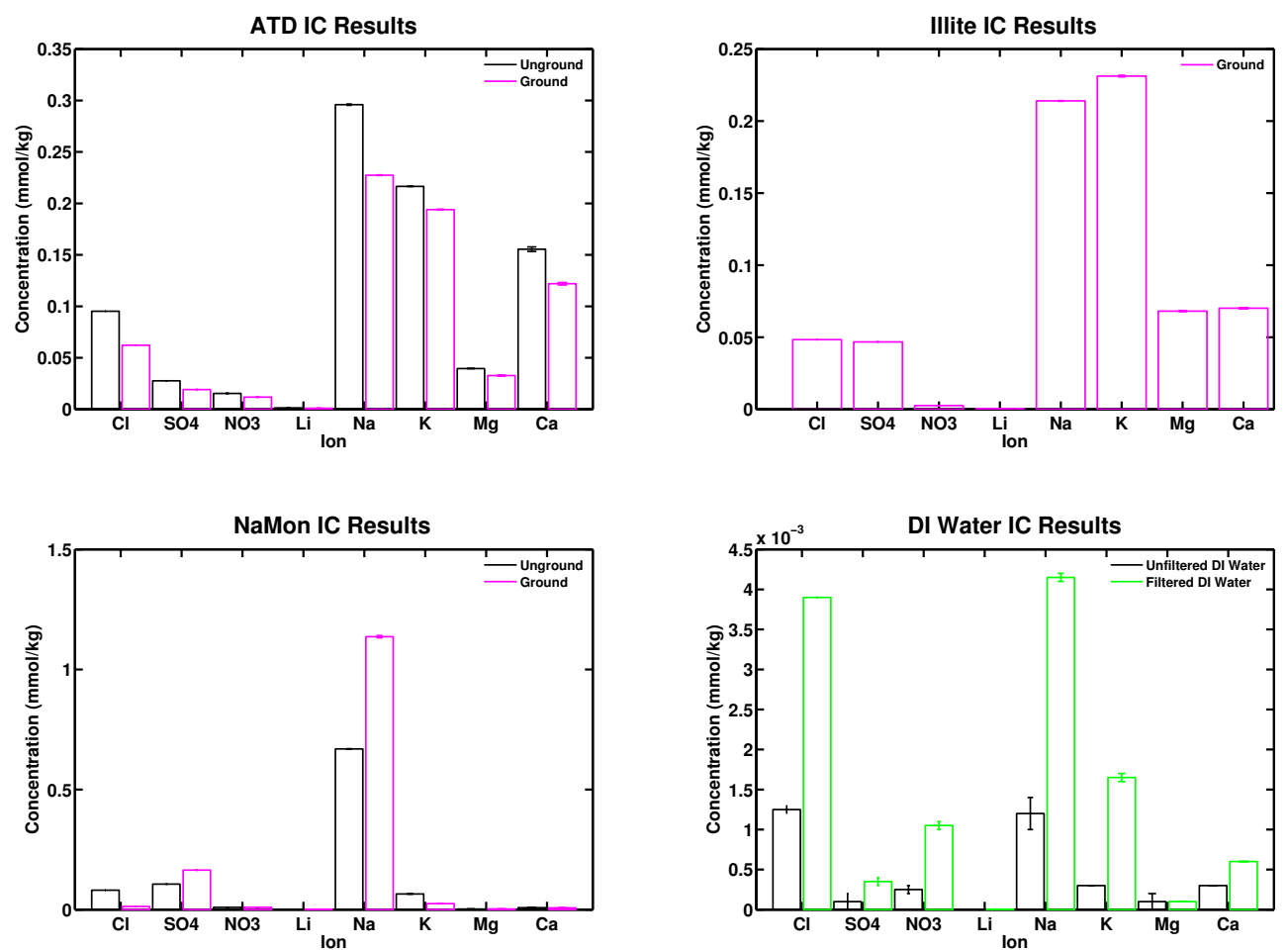

Figure 8. Results from IC analysis for filtered supernatants of ground (magenta) and unground (black) samples of the three mineral dusts. Bottom right panel shows unfiltered (black) and filtered (green) deionized (DDI) water control. The filtered slurry supernatants show significantly higher concentrations of soluble material than the DI water control.

atomizer produces droplets whose mode size is $1.5 \mu \mathrm{m}$, the resulting particles are $40-50 \mathrm{~nm}$. This size corresponds to the smaller peak in the bimodal size distributions.

Figure 9 shows the typical EDX peaks for each clay species at several mobility-equivalent sizes from the EDX detector on the JEOL 2010 Advanced High Performance TEM. There is little size dependence of soluble material content in both dry- and wet-generated mineral dusts. Wetgenerated particles have more elemental variety than drygenerated particles, further suggesting a redistribution of soluble material to the surface of particles during atomizing. The PALMS spectral data in Fig. 10 further indicates redistribution of soluble material. The figure shows histograms of the area under cation spectral peaks of $400 \mathrm{~nm}$ particles, which correlates with relative abundance of soluble material in these particles. The wet-generated particles show a shift toward smaller peak areas, suggesting less relative abundance of soluble material in large wet-generated dust particles.

\section{Discussion}

For sizes larger than $300 \mathrm{~nm}$, where correctly sized particles are expected to be found, there is agreement in the chargeand shape-corrected activation results in this study and those found in Kumar et al. (2011a) and Kumar et al. (2011b)
(Figs. 6 and 11). The only exception is for the activation of the larger mode of wet-generated ATD. Kumar et al. (2011b) report that the activated fraction of this larger wet-generated mode is $\sim 1$, but in this study, the larger mode of wetgenerated particles is observed to activate with critical supersaturations of $\sim 0.15-0.2 \%$. Dry results from this study are similar to the dry HTDMA- and CCNC-derived results reported in Herich et al. (2009). Since Herich et al. (2009) show results for particles with mobility sizes larger than $200 \mathrm{~nm}$, this agreement is more likely to be expected. Repeating the $\mathrm{CCN}$ activation experiments with cyclone impaction upstream of the DMA yields results that agree with those performed without the impactors if the necessary corrections are made. Impaction greatly reduces the concentration of multiply charged particles, bringing the post-DMA sizes closer to the desired mobility size (Figs. 6 and 7).

In this study, dry-generated particles smaller than $D_{\mathrm{m}} \sim$ $300 \mathrm{~nm}$ are found to be incorrectly sized because of the high abundance of multiply charged particles. For sizes larger than $300 \mathrm{~nm}$, the critical supersaturations in this study and Kumar et al. (2011a, b) are in agreement. The FHH fits from Kumar et al. (2011a) include data from smaller-sized particles, but these data may be biased by the size artifact observed in this study. No direct observational evidence is provided to ensure that these smaller particles are correctly sized. Since both FHH and $\kappa$-KT agree at the larger sizes, the data from these 

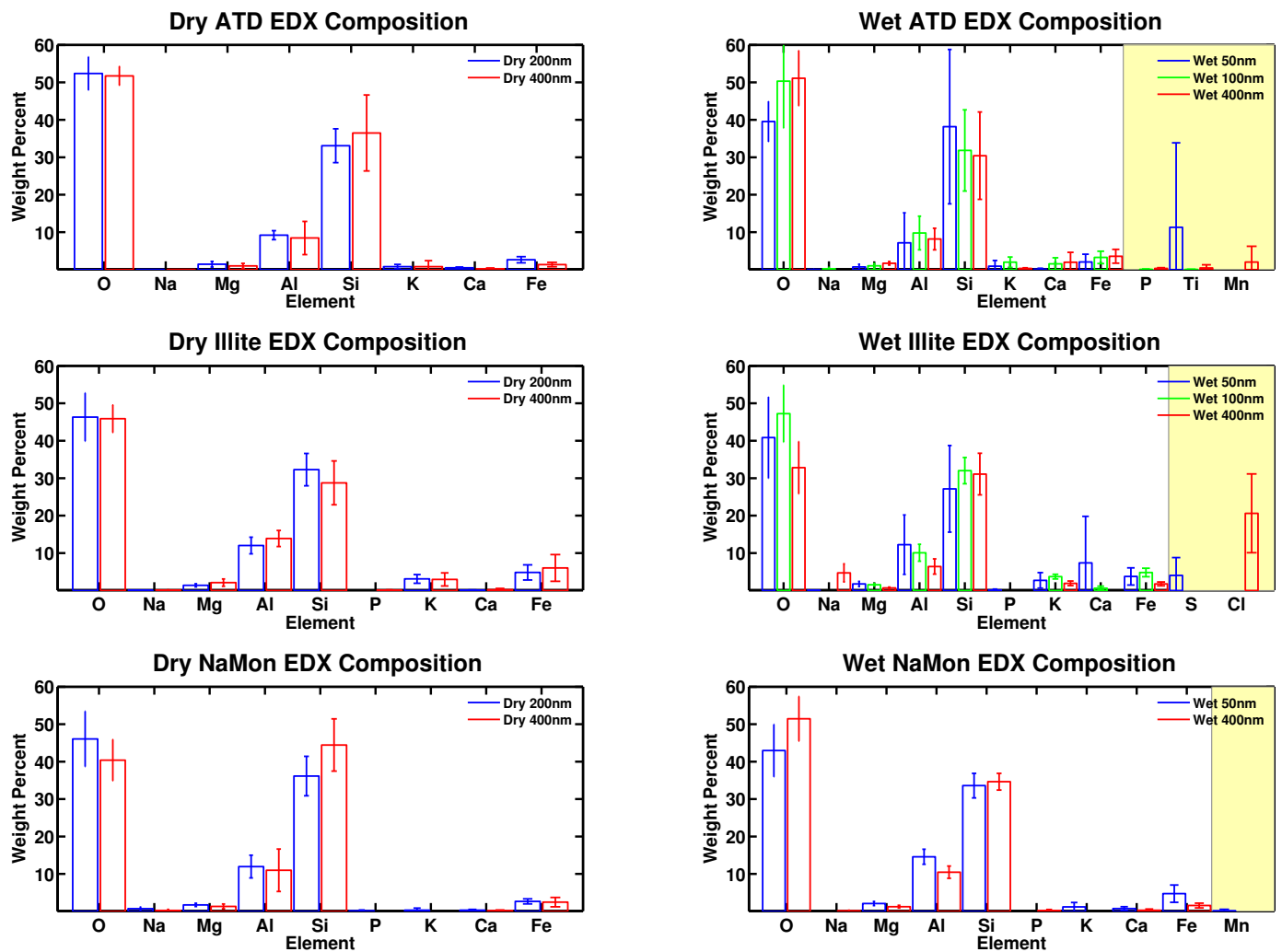

Figure 9. Elemental abundances measured using EDX indicating minimal size dependence in the composition. The wet-generated particles (right) exhibit additional elements (shaded in yellow) compared to dry particles (left), which may correspond to soluble material repartitioning. Color bars indicate size according to the legend.

sizes exhibit a narrow range of $\kappa$, and appropriate amounts of soluble material are found using IC results (see next paragraph), $\kappa-\mathrm{KT}$ is found to be the suitable framework to describe clay mineral dust nucleation activity. The value of $\kappa=0.0041$ for ATD, $\kappa=0.0072$ for illite, and $\kappa=0.0088$ for NaMon (Fig. 11). These results also show the importance of considering the appropriate data corrections to find correct values for $\kappa$. The $\kappa$ value for $200 \mathrm{~nm}$ ATD is higher than that for larger sizes even after shape correction. Because ATD is an industrially derived sample that is mechanically ground more than in either nature or in the laboratory, results for particles smaller than $300 \mathrm{~nm}$ are not representative of atmospheric particles. They may be subject to unknown artifacts, possibly compositional, that are responsible for the discontinuity. The data are provided here for reference but are omitted when determining $\kappa$.

The empirical evidence that $\kappa-\mathrm{KT}$ is the appropriate framework for dry dust nucleation also implies that soluble material on the surface of a mineral dust particle is responsible for increasing the hygroscopicity of the particle. For the samples in this study, the soluble mass fraction obtained from the IC results is $\varepsilon_{\mathrm{S}}=0.23-0.45 \%$. Assuming that the soluble material has a $\kappa_{\mathrm{s}}=0.61$ (that of ammonium sulfate) and the insoluble dust has a $\kappa_{\text {is }}=0$, the overall hygroscop- icity of the dust particle can be estimated by the mixing rule used for determining $\kappa$ for a multicomponent particle (Petters and Kreidenweis, 2007a). The resulting hygroscopicity of the dust particle imparted by the soluble component by this method is $\kappa_{\text {dust }}=0.0014-0.0027$. This estimate falls within the range of CCNC-derived values for $\kappa_{\text {dust }}$ values of $0.001-$ 0.01 . The IC-derived results can also be compared to the one estimated using the method from Kumar et al. (2009). Again assuming that the soluble material has a $\kappa_{\mathrm{S}}=0.61$ and taking the CCNC-derived $\kappa_{\text {dust }}$ values of $0.001-0.01$ observed in this study, the soluble fraction estimated by this method is $\varepsilon_{\mathrm{S}}=0.16-1.64 \%$. This range is comparable to both the $\varepsilon_{\mathrm{s}}=0.23-0.45 \%$ soluble mass fraction obtained from the IC results and the $2 \%$ soluble mass fraction of ATD reported by Vlasenko et al. (2005).

Furthermore, the range of $\kappa$ values found in this study matches the range of results $(\kappa=0.001-0.007)$ from the HTDMA and CCNC analyses of ATD, illite, and NaMon in Herich et al. (2009). The main arguments for including adsorption in CCN activity and hygroscopic growth (Kumar et al., 2009b) are (1) a higher than expected soluble fraction of dust using $\kappa$-KT and (2) differences in dust hygroscopicity under sub- and supersaturated conditions (Herich et al., 2009). Therefore, since the results from this study show that 

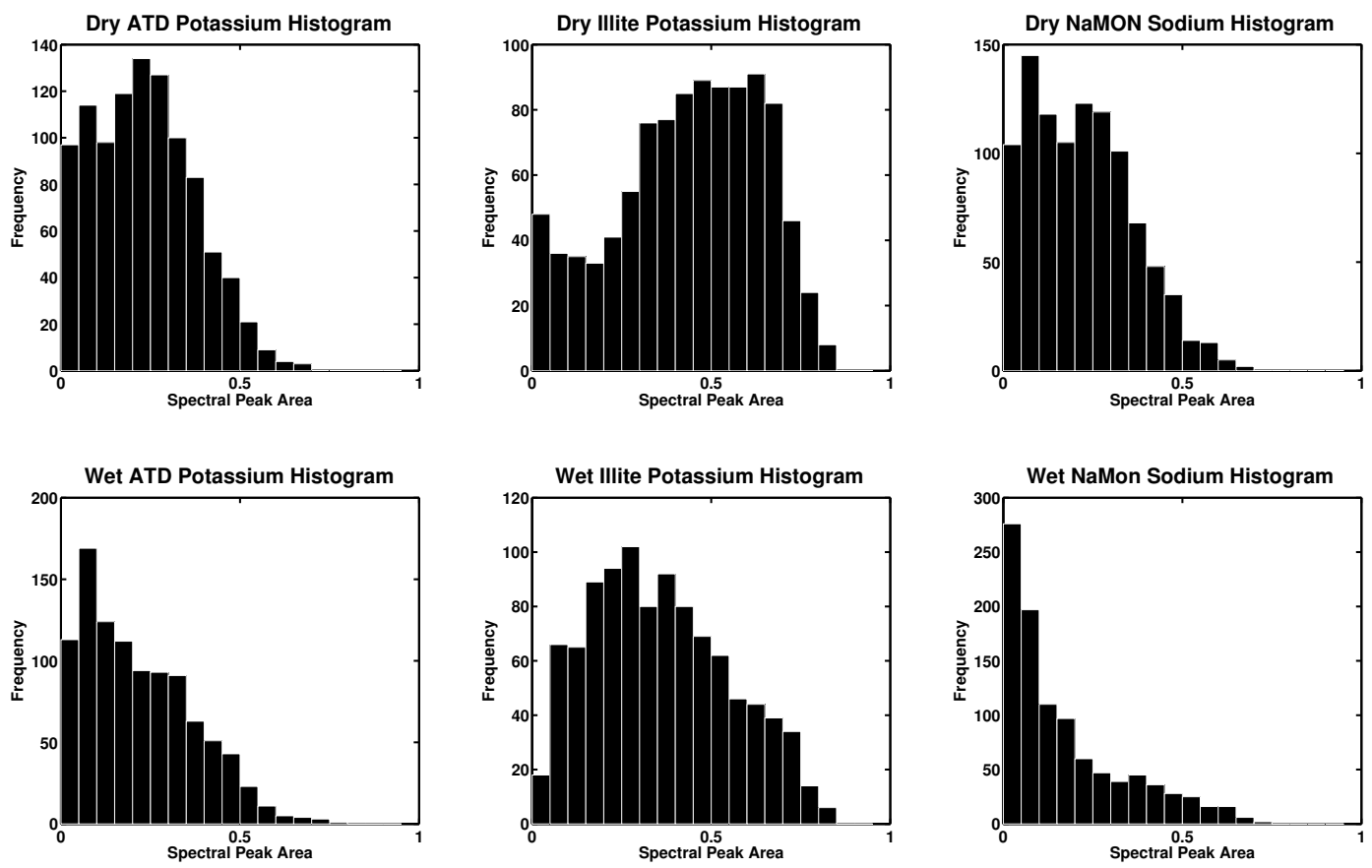

Figure 10. Histograms showing peak areas spectra collected with PALMS. The IC results (Fig. 8) show that potassium is very abundant in ATD and illite and that sodium is abundant in NaMon. Shifts toward smaller peak area (less relative abundance) can be seen in the wet-generated samples (bottom).

both of these concerns are rectified if the correct range of $\kappa=0.001-0.01$ is used and if the size distribution artifact is considered, $\kappa$-KT is found to be the appropriate framework for describing dust activation.

Additionally, atomizing mineral dust from a slurry is determined to be an unacceptable generation method to simulate saltation of fresh, unprocessed dust particles. Wet generation redistributes soluble material (Figs. 8 and 9), changing the size distributions and critical activations (Fig. 6). Especially in the smaller $(<100 \mathrm{~nm})$ mode of particles, wet generation increases the range measured $\kappa$ 's dramatically from $0.001-$ 0.01 to $0.01-0.45$. At these smaller sizes, wet generation liberates soluble material with a much higher hygroscopicity than the original dust. Despite a less dramatic difference between generation methods for NaMon (likely because it is a swelling clay), it does not avoid the size-dependent partitioning of soluble material (Fig. 10) despite its tendency to trap water between crystal layers.

\section{Conclusions and atmospheric implications}

Understanding the nucleation of droplets on atmospheric aerosols is a vital step towards describing their role in the climate system. Laboratory studies facilitate understanding $\mathrm{CCN}$ activation potential and provide insight into describing these phenomena theoretically and in climate models. This study investigates the activation potential of three dust samples in order to ascertain the suitability of dry and wet gener- ation methods and to determine whether FHH theory or $\kappa$-KT better predicts their critical supersaturations. $\kappa-\mathrm{KT}$ is found to be appropriate for describing droplet activation on mineral dust if charge and shape corrections are applied. With charge corrections, the size distributions of dust particles must be considered since abundant multiply charged particles could be misidentified as correctly sized smaller particles.

The results of this study agree with recent work (Sullivan et al., 2009, 2010; Kumar et al., 2011b) that finds that wet generation introduces a soluble mode artifact at the smaller mobility sizes (less than $\sim 100 \mathrm{~nm}$ diameter) of ATD and illite. No dry-generated mineral particles below this size are observed. The wet generation process produces a mode of soluble material liberated from the mineral. The effective $\kappa$ of these small soluble particles is different than the $\kappa$ of the dust.

For swelling clays, such as NaMon, wet generation does not change the droplet activation properties but it does change the size distribution. Particles do not dehydrate efficiently, which is akin to the different deliquescence and efflorescence points of inorganic salts. Although a secondary soluble mode is not formed for swelling clays, the added uptake of water implies that these particles are no longer unprocessed dust.

This study suggests caution in the use of wet-dispersion of mineral dust slurries when a comparison to atmospheric particles is to be made. The wet-generated ATD results show that the critical supersaturation of atomized dust can be different 


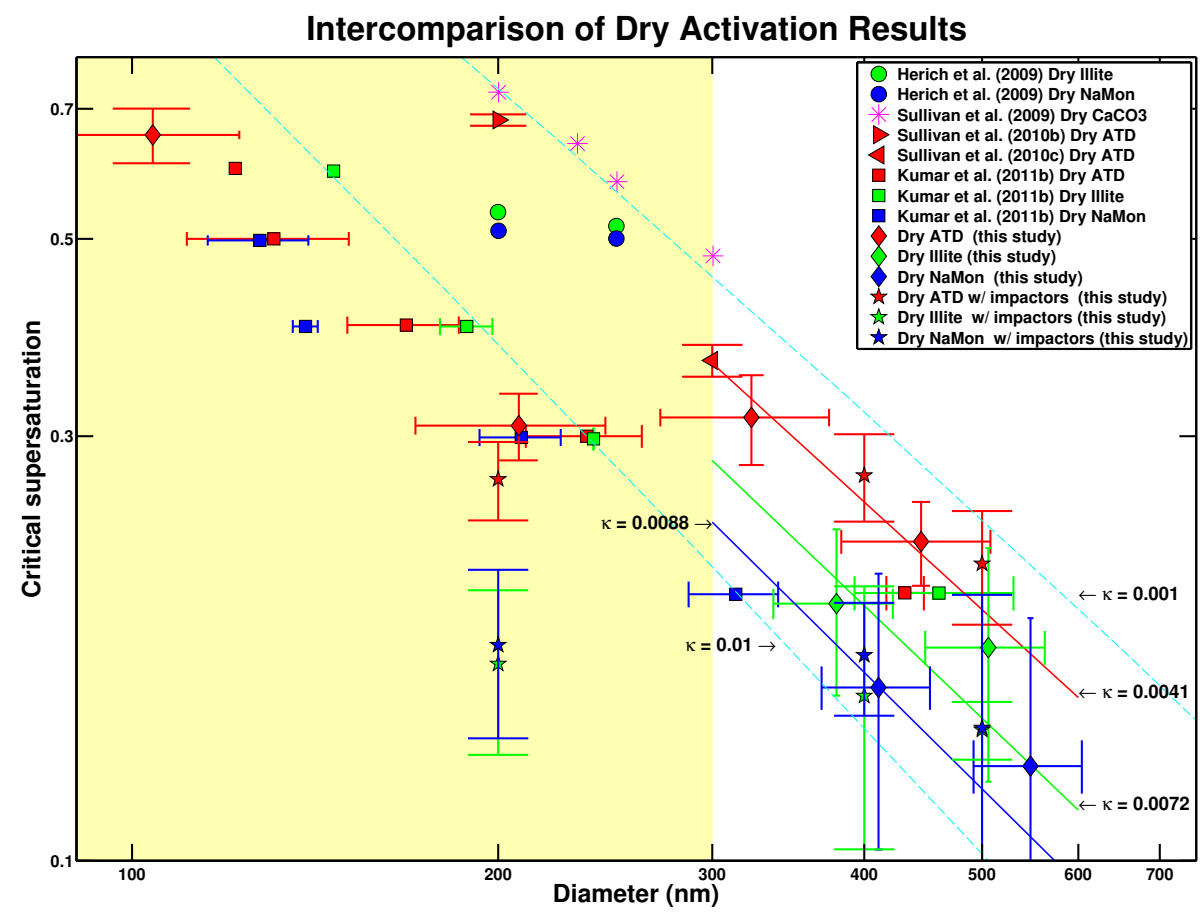

Figure 11. Critical supersaturation vs. diameter of dry-generated particles from this study compared to results from previous studies. The solid lines show fitted $\kappa$ lines for particles larger than $300 \mathrm{~nm}$. The dashed cyan lines show data that fall between $\kappa=0.001$ and $\kappa=0.01$. The data in the yellow shaded region $(<300 \mathrm{~nm})$ are unlikely to be correctly sized, as indicated by the EM results.

than that of the dry dust (a change that is not observed when the dust is simply wetted and re-dried). No known atmospheric processes lead to the redistribution of soluble material among large numbers of particles (100s or more), as is the case in atomization of a slurry. This technique inadequately represents a cloud process where mineral dust activates a droplet and then is subsequently released to the environment when the droplet evaporates, as is the case in virga. This study also suggests the simulation of cloud processed (i.e., previously wetted) mineral dust in the laboratory would be most correctly performed by activating droplets with a CCNC and then evaporating the condensed phase water downstream. This type of procedure could be useful to simulate the physical or chemical processing of particulate matter in clouds.

According to Kumar et al. (2009a), using $\kappa$-KT instead of using FHH theory in model parameterizations changes the maximum supersaturations and sensitivity of the cloud droplet number to aerosol variations in parcel model simulations. This effect is observed because FHH particles require less water uptake to reach the critical diameter than $\kappa$-KT particles and consequently deplete much less water vapor (Kumar et al., 2009a). Using FHH theory to describe activation of mineral dust will therefore bias estimates of the aerosol indirect effect when mineral dust act as CCN. Overall, the choice of parameterization in a modeling framework drastically changes results, and the empirical evidence in this study strongly supports $\kappa$-KT as the appropriate framework. Therefore, for representation in aerosol models, the results from this study indicate that $\kappa-\mathrm{KT}$ is the appropriate description for dust activation, and mineral dust should be assigned a $\kappa$ value of $0.001-0.01$.

Acknowledgements. We acknowledge NOAA OAR Climate Program Office, award number NA11OAR4310159, for funding and the MIT Center for Materials Science and Engineering for access to the EM facilities. We thank Rachel Keeler for assistance with the EM analyses and the MIT Igneous Petrology Laboratory for assistance with sample preparation.

Edited by: A. Laskin

\section{References}

Abbatt, J. P. D., Broekhuizen, K., and Kumal, P. P.: Cloud condensation nucleus activity of internally mixed ammonium sulfate/organic acid aerosol particles, Atmos. Environ., 39, 47674778, doi:10.1016/j.atmosenv.2005.04.029, 2005.

Albrecht, B. A.: Aerosols, cloud microphysics, and fractional cloudiness, Science, 245, 1227-1230, doi:10.1126/science.245.4923.1227, 1989.

Bergstrom, R. W., Schmidt, K. S., Coddington, O., Pilewskie, P., Guan, H., Livingston, J. M., Redemann, J., and Russell, P. B.: Aerosol spectral absorption in the Mexico City area: results from airborne measurements during MILAGRO/INTEX B, At- 
mos. Chem. Phys., 10, 6333-6343, doi:10.5194/acp-10-63332010, 2010

Bilde, M. and Svenningsson, B.: CCN activation of slightly soluble organics: the importance of small amounts of inorganic salt and particle phase, Tellus B, 56, 128-134, doi:10.1111/j.16000889.2004.00090.x, 2004.

BMI: Brechtel Manufacturing Incorporated Model 2002 Scanning Electrical Mobility System Manual, 5.5 ed., Hayward, CA, 2012.

Booth, B. B. B., Dunstone, N. J., Halloran, P. R., Andrews, T., and Bellouin, N.: Aerosols implicated as a prime driver of twentieth century North Atlantic climate variability, Nature, 484, 228-232, doi:10.1038/nature10946, 2012.

Brock, C. A., Cozic, J., Bahreini, R., Froyd, K. D., Middlebrook, A. M., McComiskey, A., Brioude, J., Cooper, O. R., Stohl, A., Aikin, K. C., de Gouw, J. A., Fahey, D. W., Ferrare, R. A., Gao, R.-S., Gore, W., Holloway, J. S., Hübler, G., Jefferson, A., Lack, D. A., Lance, S., Moore, R. H., Murphy, D. M., Nenes, A., Novelli, P. C., Nowak, J. B., Ogren, J. A., Peischl, J., Pierce, R. B., Pilewskie, P., Quinn, P. K., Ryerson, T. B., Schmidt, K. S., Schwarz, J. P., Sodemann, H., Spackman, J. R., Stark, H., Thomson, D. S., Thornberry, T., Veres, P., Watts, L. A., Warneke, C., and Wollny, A. G.: Characteristics, sources, and transport of aerosols measured in spring 2008 during the aerosol, radiation, and cloud processes affecting Arctic Climate (ARCPAC) Project, Atmos. Chem. Phys., 11, 2423-2453, doi:10.5194/acp-11-24232011, 2011.

Chou, C., Formenti, P., Maille, M., Ausset, P., Helas, G., Harrison, M., and Osborne, S.: Size distribution, shape, and composition of mineral dust aerosols collected during the African Monsoon Multidisciplinary Analysis Special Observation Period 0: dust and biomass-burning experiment field campaign in Niger, January 2006, J. Geophys. Res.-Atmos, 113, D00C10, doi:10.1029/2008jd009897, 2008.

Christopher, S. A., Johnson, B., Jones, T. A., and Haywood, J.: Vertical and spatial distribution of dust from aircraft and satellite measurements during the GERBILS field campaign, Geophys. Res. Lett., 36, L06806, doi:10.1029/2008GL037033, 2009.

Cicel, B. and Kranz, G.: Mechanism of montmorillonite structure degradation by percussive grinding, Clay Min., 16, 151-162, doi:10.1180/claymin.1981.016.2.03, 1981.

Coz, E., Gomez-Moreno, F. J., Pujadas, M., Casuccio, G. S., Lersch, T. L., and Artinano, B.: Individual particle characteristics of North African dust under different longrange transport scenarios, Atmos. Environ., 43, 1850-1863, doi:10.1016/j.atmosenv.2008.12.045, 2009.

DeCarlo, P. F., Slowik, J. G., Worsnop, D. R., Davidovits, P., and Jimenez, J. L.: Particle morphology and density characterization by combined mobility and aerodynamic diameter measurements. Part 1: Theory, Aerosol Sci. Tech., 38, 1185-1205, doi:10.1080/027868290903907, 2004.

Denman, K. L., Brasseur, G., Chidthaisong, A., Ciais, P., Cox, P. M., Dickinson, R. E., Hauglustaine, D., Heinze, C., Holland, E., Jacob, D., Lohmann, U., Ramachandran, S., da Silva Dias, P. L., Wofsy, S. C., and Zhang, X.: Couplings between changes in the climate system and biogeochemistry, in: Climate Change 2007: The Physical Science Basis, Contribution of Working Group I to the Fourth Assessment Report of the Intergovernmental Panel on Climate Change, edited by: Solomon, S., Qin, D., Manning, M., Chen, Z., Marquis, M., Averyt, K. B., Tignor, M., and Miller, H.
L., Cambridge University Press, Cambridge, UK and New York, NY, USA, 499-587, 2007.

Duce, R. A., Liss, P. S., Merrill, J. T., Atlas, E. L., Buat-Menard, P., Hicks, B. B., Miller, J. M., Prospero, J. M., Arimoto, R., Church, T. M., Ellis, W., Galloway, J. N., Hansen, L., Jickells, T. D., Knap, A. H., Reinhardt, K. H., Schneider, B., Soudine, A., Tokos, J. J., Tsunogai, S., Wollast, R., and Zhou, M.: The atmospheric input of trace species to the world ocean, Global Biogeochem. Cy., 5, 193-259, doi:10.1029/91GB01778, 1991.

Dusek, U., Frank, G. P., Hildebrandt, L., Curtius, J., Schneider, J., Walter, S., Chand, D., Drewnick, F., Hings, S., Jung, D., Borrmann, S., and Andreae, M. O.: Size matters more than chemistry for cloud-nucleating ability of aerosol particles, Science, 312, 1375-1378, doi:10.1126/science.1125261, 2006.

Fitzgerald, J. W.: Dependence of supersaturation spectrum of $\mathrm{CCN}$ on aerosol size distribution and composition, J. Atmos. Sci., 30, 628-634, doi:10.1175/15200469(1973)030<0628:dotsso>2.0.co;2, 1973.

Forster, P., Ramaswamy, V., Artaxo, P., Berntsen, T., Betts, R., Fahey, D. W., Haywood, J., Lean, J., Lowe, D. C., Myhre, G., Nganga, J., Prinn, R., Raga, G., Schulz, M., and Van Dorland, R.: Changes in atmospheric constituents and in radiative forcing, in: Climate Change 2007: The Physical Science Basis, Contribution of Working Group I to the Fourth Assessment Report of the Intergovernmental Panel on Climate Change, edited by: Solomon, S., Qin, D., Manning, M., Chen, Z., Marquis, M., Averyt, K. B., Tignor, M., and Miller, H. L., Cambridge University Press, Cambridge, UK and New York, NY, USA, 129-234, 2007.

Foster, M. D.: Geochemical studies of clay minerals, 2. Relation between ionic substitution and swelling in montmorillonites, Am. Mineral., 38, 994-1006, 1953.

Friedman, B., Zelenyuk, A., Beranek, J., Kulkarni, G., Pekour, M., Gannet Hallar, A., McCubbin, I. B., Thornton, J. A., and Cziczo, D. J: Aerosol measurements at a high-elevation site: composition, size, and cloud condensation nuclei activity, Atmos. Chem. Phys., 13, 11839-11851, doi:10.5194/acp-13-11839-2013, 2013.

Furutani, H., Dall'osto, M., Roberts, G. C., and Prather, K. A.: Assessment of the relative importance of atmospheric aging on $\mathrm{CCN}$ activity derived from field observations, Atmos. Environ., 42, 13, 3130-3142, doi:10.1016/j.atmosenv.2007.09.024, 2008.

Ganor, E. and Foner, H. A.: The mineralogical and chemical properties and the behaviour of Aeolian Saharan dust over Israel, Envir. Sci. Tech. Lib., 11, 163-172, 1996.

Ganor, E. and Mamane, Y.: Transport of Saharan dust across the eastern Mediterranean, Atmos. Environ., 16, 581-587, doi:10.1016/0004-6981(82)90167-6, 1982.

Ginoux, P., Prospero, J. M., Gill, T. E., Hsu, N. C., and Zhao, M.: Global-scale attribution of anthropogenic and natural dust sources and their emission rates based on MODIS Deep Blue aerosol products, Rev. Geophys., 50, RG3005, doi:10.1029/2012rg000388, 2012.

Hansen, J., Sato, M., Kharecha, P., and von Schuckmann, K.: Earth's energy imbalance and implications, Atmos. Chem. Phys., 11, 13421-13449, doi:10.5194/acp-11-13421-2011, 2011.

Henson, B. F.: An adsorption model of insoluble particle activation: Application to black carbon, J. Geophys. Res., 112, D24S16, doi:10.1029/2007JD008549, 2007.

Herich, H., Tritscher, T., Wiacek, A., Gysel, M., Weingartner, E., Lohmann, U., Baltensperger, U., and Cziczo, D. J.: Water up- 
take of clay and desert dust aerosol particles at sub- and supersaturated water vapor conditions, Phys. Chem. Chem. Phys., 11, 7804-7809, doi:10.1039/b901585j, 2009.

Hurd, F. K. and Mullins, J. C.: Aerosol size distribution from ion mobility, J. Coll. Sci. Imp. U. Tok., 17, 91-100, doi:10.1016/0095-8522(62)90001-6, 1962.

Junge, C. and McLaren, E.: Relationship of cloud nuclei spectra to aerosol size distribution and composition, J. Atmos. Sci., 28, 382-390, doi:10.1175/15200469(1971)028<0382:rocnst>2.0.co;2, 1971.

Koehler, K. A., Kreidenweis, S. M., DeMott, P. J., Petters, M. D., Prenni, A. J., and Carrico, C. M.: Hygroscopicity and cloud droplet activation of mineral dust aerosol, Geophys. Res. Lett., 36, L08805, doi:10.1029/2009g1037348, 2009.

Kohler, H.: The nucleus in and the growth of hygroscopic droplets, Trans. Faraday Soc., 32, 1152-1161, doi:10.1039/tf9363201152, 1936.

Kumar, P., Sokolik, I. N., and Nenes, A.: Parameterization of cloud droplet formation for global and regional models: including adsorption activation from insoluble CCN, Atmos. Chem. Phys., 9, 2517-2532, doi:10.5194/acp-9-2517-2009, 2009a.

Kumar, P., Nenes, A., and Sokolik, I. N.: Importance of adsorption for CCN activity and hygroscopic properties of mineral dust aerosol, Geophys. Res. Lett., 36, L24804, doi:10.1029/2009GL040827, 2009b.

Kumar, P., Sokolik, I. N., and Nenes, A.: Measurements of cloud condensation nuclei activity and droplet activation kinetics of fresh unprocessed regional dust samples and minerals, Atmos. Chem. Phys., 11, 3527-3541, doi:10.5194/acp-11-3527-2011, 2011a.

Kumar, P., Sokolik, I. N., and Nenes, A.: Cloud condensation nuclei activity and droplet activation kinetics of wet processed regional dust samples and minerals, Atmos. Chem. Phys., 11, 8661-8676, doi:10.5194/acp-11-8661-2011, 2011 b.

Lafon, S., Sokolik, I. N., Rajot, J. L., Caquineau, S., and Gaudichet, A.: Characterization of iron oxides in mineral dust aerosols: implications for light absorption, J. Geophys. Res.-Atmos, 111, D21207, doi:10.1029/2005jd007016, 2006.

Lambe, A. T., Onasch, T. B., Massoli, P., Croasdale, D. R., Wright, J. P., Ahern, A. T., Williams, L. R., Worsnop, D. R., Brune, W. H., and Davidovits, P.: Laboratory studies of the chemical composition and cloud condensation nuclei $(\mathrm{CCN})$ activity of secondary organic aerosol (SOA) and oxidized primary organic aerosol (OPOA), Atmos. Chem. Phys., 11, 8913-8928, doi:10.5194/acp11-8913-2011, 2011.

Lance, S., Medina, J., Smith, J. N., and Nenes, A.: Mapping the operation of the DMT Continuous Flow CCN counter, Aerosol Sci. Tech., 40, 242-254, doi:10.1080/02786820500543290, 2006.

Lathem, T. L., Beyersdorf, A. J., Thornhill, K. L., Winstead, E. L., Cubison, M. J., Hecobian, A., Jimenez, J. L., Weber, R. J., Anderson, B. E., and Nenes, A.: Analysis of CCN activity of Arctic aerosol and Canadian biomass burning during summer 2008, Atmos. Chem. Phys., 13, 2735-2756, doi:10.5194/acp-13-27352013, 2013.

Lee, S., Ghim, Y. S., Kim, S. W., and Yoon, S. C.: Effect of biomass burning and regional background aerosols on CCN activity derived from airborne in-situ measurements, Atmos. Environ., 44, 39, 5227-5236, doi:10.1016/j.atmosenv.2010.08.044, 2010.
Logan, T., Xi, B., Dong, X., Obrecht, R., Li, Z., and Cribb, M.: A study of Asian dust plumes using satellite, surface, and aircraft measurements during the INTEX-B field experiment, J. Geophys. Res., 115, D00K25, doi:10.1029/2010JD014134, 2010.

Lyapustin, A., Gatebe, C. K., Kahn, R., Brandt, R., Redemann, J., Russell, P., King, M. D., Pedersen, C. A., Gerland, S., Poudyal, R., Marshak, A., Wang, Y., Schaaf, C., Hall, D., and Kokhanovsky, A.: Analysis of snow bidirectional reflectance from ARCTAS Spring-2008 Campaign, Atmos. Chem. Phys., 10, 4359-4375, doi:10.5194/acp-10-4359-2010, 2010.

Ma, C. J., Tohno, S., Kasahara, M., and Hayakawa, S., Properties of the size-resolved and individual cloud droplets collected in western Japan during the Asian dust storm event, Atmos. Environ., 38, 4519-4529, doi:10.1016/j.atmosenv.2004.05.032, 2004.

McDonald, J. E.: Cloud nucleation on insoluble particles, J. Atmos. Sci., 21, 109-116, doi:10.1175/15200469(1964)021<0109:cnoip>2.0.co;2, 1964.

McFarquhar, G. M., Ghan, S., Verlinde, J., Korolev, A., Strapp, J. W., Schmid, B., Tomlinson, J. M., Wolde, M., Brooks, S. D., Cziczo, D., Dubey, M. K., Fan, J., Flynn, C., Gultepe, I., Hubbe, J., Gilles, M. K., Laskin, A., Lawson, P., Leaitch, W. R., Liu, P., Liu, X., Lubin, D., Mazzoleni, C., Macdonald, A.-M., Moffet, R. C., Morrison, H., Ovchinnikov, M., Shupe, M. D., Turner, D. D., Xie, S., Zelenyuk, A., Bae, K., Freer, M., and Glen, A.: Indirect and semi-direct aerosol campaign, B. Am. Meteorol. Soc., 92, 183-201, 2011.

Middlebrook, A. M., Thomson, D. S., and Murphy, D. M.: On the purity of laboratory generated sulfuric acid droplets and ambient particles studied by laser mass spectrometry, Aerosol Sci. Tech., 27, 293-307, 1997.

Moore, R., Nenes, A., and Medina, J.: Scanning Mobility CCN Analysis - A method for fast measurements of size resolved CCN distributions and activation kinetics, Aerosol Sci. Tech., 44, 861871, 2010.

Moore, R. H., Bahreini, R., Brock, C. A., Froyd, K. D., Cozic, J., Holloway, J. S., Middlebrook, A. M., Murphy, D. M., and Nenes, A.: Hygroscopicity and composition of Alaskan Arctic CCN during April 2008, Atmos. Chem. Phys., 11, 11807-11825, doi:10.5194/acp-11-11807-2011, 2011.

Murphy, D. M. and Thomson, D. S.: Laser ionization mass spectroscopy of single aerosol particles, Aerosol Sci. Tech., 22, 237 249, doi:10.1080/02786829408959743, 1995.

Noble, C. A. and Prather, K. A.: Real-time measurement of correlated size and composition profiles of individual atmospheric aerosol particles, Environ. Sci. Tech., 30, 2667-2680, doi:10.1021/es950669j, 1996.

Pett-Ridge, J. C.: Contributions of dust to phosphorus cycling in tropical forests of the Luquillo Mountains, Puerto Rico, Biogeochemistry, 94, 63-80, doi:10.1007/s10533-009-9308-x, 2009.

Petters, M. D. and Kreidenweis, S. M.: A single parameter representation of hygroscopic growth and cloud condensation nucleus activity, Atmos. Chem. Phys., 7, 1961-1971, doi:10.5194/acp-71961-2007, 2007a.

Petters, M. D., Prenni, A. J., Kreidenweis, S. M., and DeMott, P. J.: On measuring the critical diameter of cloud condensation nuclei using mobility selected aerosol, Aerosol Sci. Tech., 41, 907-913, doi:10.1080/02786820701557214, 2007b.

Poppe, L. J., Coastal and Marine Geology Program (Geological Survey), and Geological Survey (US): A laboratory manual for $\mathrm{x}$ - 
ray powder diffraction, in: US Geological Survey open-file report 01-41, US Geological Survey, Coastal and Marine Geology Program, Woods Hole, Mass., 2001.

Pruppacher, H. R. and Klett, J. D.: Microphysics of Clouds and Precipitation, 2nd edn., Atmospheric and Oceanographic Sciences Library, 18, Kluwer Academic Publishers, Dordrecht, Boston, MA, 954, 1997.

Raymond, T. M. and Pandis, S. N.: Cloud activation of singlecomponent organic aerosol particles, J. Geophys. Res.-Atmos, 107, 4787, doi:10.1029/2002jd002159, 2002.

Raymond, T. M. and Pandis, S. N.: Formation of cloud droplets by multicomponent organic particles, J. Geophys. Res.-Atmos, 108, 4469, doi:10.1029/2003jd003503, 2003.

Roberts, G. C. and Nenes, A.: A continuous-flow streamwise thermal-gradient $\mathrm{CCN}$ chamber for atmospheric measurements, Aerosol Sci. Tech., 39, 206-221, doi:10.1080/027868290913988, 2005.

Rudich, Y., Donahue, N. M., and Mentel, T. F.: Aging of organic aerosol: bridging the gap between laboratory and field studies, Annu. Rev. Phys. Chem., 58, 321-352, 2007.

Seinfeld, J. H. and Pandis, S. N.: Atmospheric Chemistry and Physics: From Air Pollution to Climate Change, 2nd edn., Wiley, Hoboken, NJ, 1203, 2006.

Shaw, R. W. and Paur, R. J.: Composition of aerosol-particles collected at rural sites in the Ohio River Valley, Atmos. Environ., 17, 2031-2044, doi:10.1016/0004-6981(83)90360-8, 1983.

Sullivan, R. C., Moore, M. J. K., Petters, M. D., Kreidenweis, S. M., Roberts, G. C., and Prather, K. A.: Effect of chemical mixing state on the hygroscopicity and cloud nucleation properties of calcium mineral dust particles, Atmos. Chem. Phys., 9, 33033316, doi:10.5194/acp-9-3303-2009, 2009.

Sullivan, R. C., Moore, M. J. K., Petters, M. D., Kreidenweis, S. M., Qafoku, O., Laskin, A., Roberts, G. C., and Prather, K. A.: Impact of particle generation method on the apparent hygroscopicity of insoluble mineral particles, Aerosol Sci. Tech., 44, 830846, 2010a.

Sullivan, R. C., Petters, M. D., DeMott, P. J., Kreidenweis, S. M., Wex, H., Niedermeier, D., Hartmann, S., Clauss, T., Stratmann, F., Reitz, P., Schneider, J., and Sierau, B.: Irreversible loss of ice nucleation active sites in mineral dust particles caused by sulphuric acid condensation, Atmos. Chem. Phys., 10, 1147111487, doi:10.5194/acp-10-11471-2010, 2010b.
Sullivan, R. C., Minambres, L., DeMott, P. J., Prenni, A. J., Carrico, C. M., Levin, E. J. T., and Kreidenweis, S. M.: Chemical processing does not always impair heterogeneous ice nucleation of mineral dust particles, Geophys. Res. Lett., 37, L24805, doi:10.1029/2010g1045540, 2010c.

Tegen, I., Lacis, A. A., and Fung, I.: The influence on climate forcing of mineral aerosols from disturbed soils, Nature, 380, 419422, doi:10.1038/380419a0, 1996.

Twomey, S.: Influence of pollution on shortwave albedo of clouds, J. Atmos. Sci., 34, 1149-1152, doi:10.1175/15200469(1977)034<1149:tiopot>2.0.co;2, 1977.

Usher, C. R., Michel, A. E., and Grassian, V. H.: Reactions on mineral dust, Chem. Rev., 103, 4883-4939, doi:10.1021/cr020657y, 2003.

Vlasenko, A., Sjögren, S., Weingartner, E., Gäggeler, H. W., and Ammann, M.: Generation of Submicron Arizona Test Dust Aerosol: Chemical and Hygroscopic Properties, Aerosol Sci. Tech., 39, 452-460, 2005.

Wenk, H.-R. and Bulakh, A. G.: Minerals: their Constitution and Origin, Cambridge University Press, Cambridge, New York, xxii, 646, 2004.

Wiedensohler, A.: An approximation of the bipolar chargedistribution for particles in the sub-micron size range, J. Aerosol. Sci., 19, 387-389, doi:10.1016/0021-8502(88)90278-9, 1988.

Wong, J. P. S., Lee, A. K. Y., Slowik, J. G., Cziczo, D. J., Leaitch, W. R., Macdonald, A., and Abbatt, J. P. D.: Oxidation of ambient biogenic secondary organic aerosol by hydroxyl radicals: effects on cloud condensation nuclei activity, Geophys. Res. Lett., 38, L22805, doi:10.1029/2011g1049351, 2011.

Yu, H., Kaufman, Y. J., Chin, M., Feingold, G., Remer, L. A., Anderson, T. L., Balkanski, Y., Bellouin, N., Boucher, O., Christopher, S., DeCola, P., Kahn, R., Koch, D., Loeb, N., Reddy, M. S., Schulz, M., Takemura, T., and Zhou, M.: A review of measurement-based assessments of the aerosol direct radiative effect and forcing, Atmos. Chem. Phys., 6, 613-666, doi:10.5194/acp-6-613-2006, 2006.

Zhang, X. Y., Wang, Y. Q., Niu, T., Zhang, X. C., Gong, S. L., Zhang, Y. M., and Sun, J. Y.: Atmospheric aerosol compositions in China: spatial/temporal variability, chemical signature, regional haze distribution and comparisons with global aerosols, Atmos. Chem. Phys., 12, 779-799, doi:10.5194/acp12-779-2012, 2012. 